\title{
Avaliação de diferentes marcadores para a determinação da digestibilidade e taxa de passagem do alimento em suínos
}

\author{
LILIANA LOTUFO OETTING
}

Dissertação apresentada ao Centro de Energia Nuclear na Agricultura, Universidade de São Paulo, para obtenção do título de Mestre em Ciências, Área de Concentração: Energia Nuclear na Agricultura.

PIRACICABA

Estado de São Paulo - Brasil

Maio - 2002 


\title{
Avaliação de diferentes marcadores para a determinação da digestibilidade e taxa de passagem do alimento em suínos
}

\author{
LILIANA LOTUFO OETTING \\ Zootecnista
}

Orientador: Prof. Dr. ADIBE LUIZ ABDALLA

Dissertação apresentada ao Centro de Energia Nuclear na Agricultura, Universidade de São Paulo, para obtenção do título de Mestre em Ciências, Área de Concentração: Energia Nuclear na Agricultura.

\author{
PIRACICABA \\ Estado de São Paulo - Brasil \\ Maio - 2002
}


Dados Internacionais de Catalogação na Publicação (CIP) Seção Técnica de Biblioteca - CENA/USP

Oetting, Liliana Lotufo

Avaliação de diferentes marcadores para a determinação da digestibilidade e taxa de passagem do alimento em suínos / Liliana Lotufo Oetting. - - Piracicaba, 2002. $57 p$.

Dissertação (mestrado) - - Centro de Energia Nuclear na Agricultura, 2002.

1. Avaliação nutricional animal 2. Espectrometria 3. Técnicas nucleares 4 . Terras raras I. Título

CDU 636.085.2:546.65 


\section{Aos meus pais,}

Afonso e Lúcia, que estiveram sempre presentes, me apoiando e incentivando, nos momentos importantes da minha vida;

\section{Aos meus irmãos,}

Luís Afonso e Luciano, pelo carinho e amizade;

\section{Aos meus sogros,}

Seiji e Solange, por sempre me receberem de braços abertos;

\section{À minha mãe de profissão,}

Jacinta, que me mostrou o caminho e me deu a oportunidade de seguir em frente, pelo qual serei eternamente grata;

com muito amor e gratidão,

DEDICO

\section{Ao meu marido,}

Carlos, que mais do que ninguém contribuiu para que eu realizasse mais essa etapa da minha vida, como conselheiro e um grande companheiro de todos os momentos;

com muito amor e gratidão, 
AGRADECIMENTOS:

Á CAPES, pelo período de bolsa concedida;

Ao Prof. Dr. Adibe Luiz Abdalla, pela confiança e pela grande disposição como orientador;

Ao Prof. Dr. Valdomiro Shigueru Miyada, pela fundamental colaboração no experimento com o fornecimento dos animais e da ração;

Ao Prof. Dr. Virgílio F. do Nascimento, pela paciência e ajuda imprescindível na análise dos marcadores;

À Dra. Ana Rita de A. Nogueira, pelas sugestões, esclarecimentos e colaboração na análise dos marcadores;

Ao Prof. Dr. Irineu U. Packer, pelos conselhos e sugestões na análise estatística;

À Raquel S. Dias, minha grande companheira de mestrado, pela valiosa amizade, apoio e compreensão nos diversos momentos que passamos juntas;

Aos companheiros do Laboratório de Nutrição Animal, Ana Paula, Aparecido, Carina, Cibele, Eduardo, Ives, Lúcio, Mariana, Patrícia e Sarita, pelo apoio e amizade durante todo o curso;

Aos funcionários do laboratório, Lécio e Regina, pela ajuda prestada no experimento;

Ao funcionário do Setor de Suinocultura, Sr. Pires, que ajudou na pesagem e transporte dos animais; 
Aos amigos Adriana Figueiredo, Adriana Pedroso, Flávio Longo e Renata Duarte, pelos conselhos e amizade durante todo esse tempo;

Àqueles que de alguma maneira, direta ou indiretamente, contribuíram para a realização deste trabalho, a minha enorme gratidão. 


\section{SUMÁRIO}

Página

LISTA DE FIGURAS........................................................................... vii

LISTA DE TABELAS.................................................................................. ix

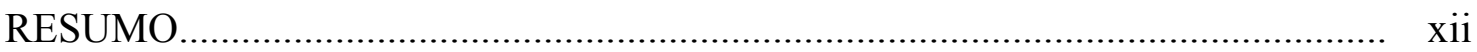

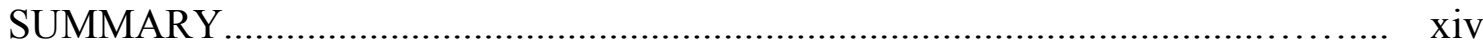

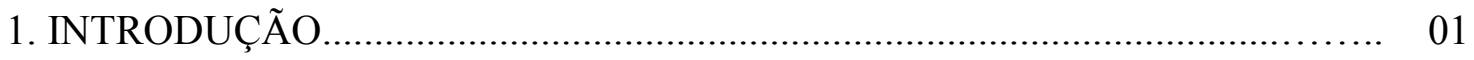

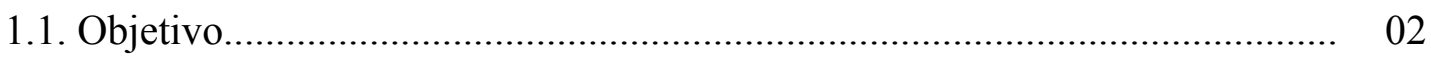

2. REVISÃO DE LITERATURA................................................................. 03

2.1. Marcadores dietéticos...................................................................... 03

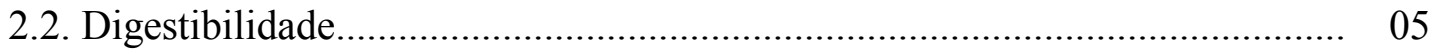

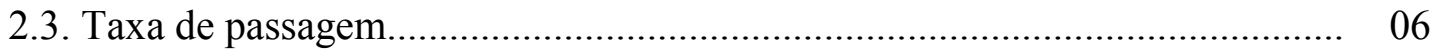

2.4. Técnicas analíticas........................................................................... 06

3. MATERIAL E MÉTODOS.................................................................... 08

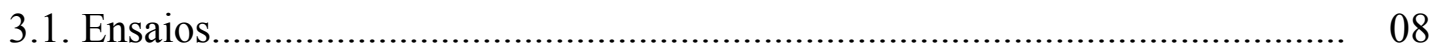

3.2. Local e animais............................................................................... 09

3.3. Ração experimental............................................................................... 09

3.4. Adição dos marcadores....................................................................... 10

3.5. Ensaio de digestibilidade ................................................................. 11

3.5.1. Coleta total de fezes............................................................. 14

3.5.2. Coleta parcial de fezes.................................................................... 14

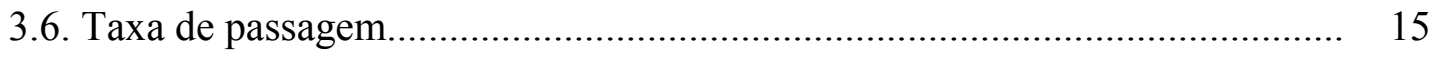

3.6.1. Taxa de passagem I.................................................................. 16

3.6.2. Taxa de passagem II................................................................ 17

3.7. Análises laboratoriais............................................................................... 18

3.8. Análise estatística............................................................................... 20

3.8.1. Ensaio de digestibilidade ..................................................... 20

3.8.2. Taxa de passagem.................................................................. 20 
4. RESULTADOS E DISCUSSÃO ............................................................... 22

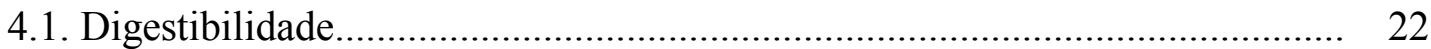

4.1.1. Coleta total de fezes...................................................................... 22

4.1.2. Coleta parcial de fezes................................................................... 24

4.1.3. Comparação entre a coleta total e parcial de fezes.............................. 29

4.2.Taxa de passagem............................................................................... 36

4.2.1. Taxa de passagem I................................................................... 36

4.2.2. Taxa de passagem II.................................................................... 41

4.2.3. Comparação entre as taxas de passagem I e II................................... 46

5. CONCLUSÃO

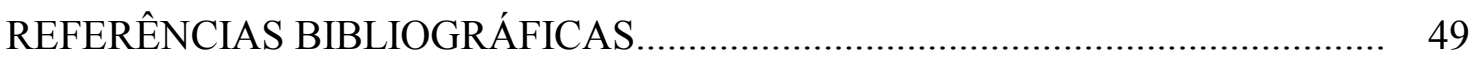




\section{LISTA DE FIGURAS}

Página

1 Cronograma de execução dos dois experimentos de Taxa de Passagem (I e II) e do Ensaio de Digestibilidade.

2 Cronograma de execução do Ensaio de Digestibilidade utilizando as duas metodologias (coleta total e coleta parcial de fezes) simultaneamente

3 Curva de excreção do cromo, analisado por ICP-OES, para os quatro animais na Taxa de Passagem I.

4 Curva de excreção do cromo, analisado por ED-XRF, para os quatro animais na Taxa de Passagem I

5 Curva de excreção do lantânio, analisado por ICP-OES, para os quatro animais na Taxa de Passagem I............................................. 38

6 Curva de excreção do lantânio, analisado por ED-XRF, para os quatro animais na Taxa de Passagem I........................................................ 38

7 Curva de excreção do itérbio, analisado por ICP-OES, para os quatro animais na Taxa de Passagem I .................................................... 39

8 Curva de excreção do itérbio, analisado por ED-XRF, para os quatro animais na Taxa de Passagem I........................................................ 39

9 Curva de excreção cromo, analisado por ICP-OES, para os quatro animais na Taxa de Passagem II...................................................... 42 
10 Curva de excreção cromo, analisado por ED-XRF, para os quatro animais na Taxa de Passagem II........................................................

11 Curva de excreção lantânio, analisado por ICP-OES, para os quatro animais na Taxa de Passagem II...........................................................

12 Curva de excreção lantânio, analisado por ED-XRF, para os quatro animais na Taxa de Passagem II.....................................................

13 Curva de excreção itérbio, analisado por ICP-OES, para os quatro animais na Taxa de Passagem II..........................................................

14 Curva de excreção itérbio, analisado por ED-XRF, para os quatro animais na Taxa de Passagem II........................................................ 


\section{LISTA DE TABELAS}

Página

1 Composição percentual da dieta basal utilizada nos ensaios de digestibilidade e taxa de passagem com suínos em terminação, com os respectivos valores de energia bruta (EB), matéria seca (MS) e proteína bruta $(\mathrm{PB})$ obtidos na análise bromatológica

2 Cálculo do consumo restrito de ração para o Ensaio de Digestibilidade, a partir do peso metabólico dos suínos

3 Cálculo do consumo restrito de ração para a Taxa de Passagem I, a partir do peso metabólico dos suínos....

4 Cálculo do consumo restrito de ração para a Taxa de Passagem II, a partir do peso metabólico dos suínos.

5 Parâmetros operacionais utilizados no ICP-OES para análise de cromo, lantânio e itérbio em amostras de ração e fezes de suínos.........

$6 \quad$ Análise de energia bruta (EB), matéria seca (MS) e proteína bruta (PB) das fezes obtidas no ensaio de digestibilidade com suínos em terminação

7 Consumo total de ração e produção total de fezes, com valores expressos em matérias seca (MS), durante os cinco dias de coleta de fezes do ensaio de digestibilidade com suínos.

8 Coeficientes de digestibilidade aparente da energia bruta (CD-EB), matéria seca (CD-MS) e proteína bruta (CD-PB) de suínos em terminação obtidos pelo método da coleta total de fezes. 
9 Concentração dos três marcadores (cromo, lantânio e itérbio) na ração experimental obtida pelas duas técnicas analíticas (ICP-OES e ED$\mathrm{XRF}$ ).

10 Concentração de cada marcador (cromo, lantânio e itérbio) nas fezes dos 12 animais obtida através de duas técnicas analíticas (ICP-OES e ED-XRF)

11 Coeficientes de digestibilidade da energia bruta (\%) dos 12 animais, obtidos para cada marcador analisado por ICP-OES e ED-XRF

12 Coeficientes de digestibilidade da matéria seca (\%) dos 12 animais, obtidos para cada marcador analisado por ICP-OES e ED-XRF....

13 Coeficientes de digestibilidade da proteína bruta (\%) dos 12 animais, obtidos para cada marcador analisado por ICP-OES e ED-XRF.

14 Comparação entre as médias dos coeficientes de digestibilidade (CD) da energia bruta (EB), matéria seca $(\mathrm{MS})$ e proteína bruta (PB) obtidas pelo método da coleta total e parcial de fezes utilizando três marcadores ( $\mathrm{Cr}$, La, e $\mathrm{Yb}$ ) e duas técnicas analíticas (ICP-OES e ED$\mathrm{XRF})$.

15 Comparação entre as médias dos coeficientes de digestibilidade (CD) da energia bruta (EB), matéria seca (MS) e proteína bruta (PB) obtidas pelo método da coleta total e parcial de fezes utilizando três marcadores ( $\mathrm{Cr}$, La e $\mathrm{Yb}$ ) e duas técnicas analíticas (ICP-OES e EDXRF), e considerando a quantidade esperada de marcador na ração.

16 Porcentagem de recuperação dos marcadores nas fezes (analisados por ICP-OES e ED-XRF), considerando a concentração analisada de marcadores na ração 
17 Comparação entre a porcentagem de recuperação dos marcadores nas fezes (analisados por ICP-OES e ED-XRF) considerando a concentração esperada e a concentração analisada de marcadores na ração............................................................................

18 Equações de regressão linear e comparação dos valores de "b" para cada tratamento na Taxa de Passagem I...............................................

19 Equações de regressão linear e comparação dos valores de "b" para cada tratamento na Taxa de Passagem II.............................................

20 Comparação dos valores médios do "b" da equação de regressão linear obtidos nas Taxas de Passagem I e II para cada um dos tratamentos. 


\title{
Avaliação de diferentes marcadores para a determinação da digestibilidade e taxa de passagem do alimento em suínos
}

\author{
Autora: LILIANA LOTUFO OETTING \\ Orientador: Prof. Dr. ADIBE LUIZ ABDALLA
}

\section{RESUMO}

O objetivo do trabalho foi (1) avaliar a utilização do óxido crômico, lantânio e itérbio como marcadores dietéticos para a determinação da digestibilidade, (2) determinar a taxa de passagem através desses três marcadores, e (3) comparar duas técnicas analíticas (ICP-OES e ED-XRF) na análise dos marcadores.

No ensaio de digestibilidade foram utilizadas 12 fêmeas suínas com idade inicial e final de 133 e 153 dias, respectivamente, sendo que os sete tratamentos envolvidos representam a combinação das duas técnicas analíticas (ICP-OES e ED$\mathrm{XRF}$ ) com os três marcadores utilizados na coleta parcial de fezes (Cr, La, Yb), e um tratamento padrão (coleta total de fezes).

$\mathrm{Na}$ taxa de passagem foram utilizados quatro animais em cada ensaio e as coletas tiveram início após o fornecimento de uma dose única (Taxa de Passagem I) ou a interrupção do fornecimento constante dos marcadores na dieta (Taxa de Passagem II). Os seis tratamentos avaliados corresponderam à combinação dos três marcadores com as duas técnicas analíticas. Para a comparação das curvas obtidas foi feita uma análise de regressão para cada tratamento e os valores de inclinação das retas ("b") obtidas por equações de regressão linear foram então comparados pelo teste de Tukey.

Os coeficientes de digestibilidade obtidos com os marcadores (coleta parcial de fezes) foram significativamente inferiores $(\mathrm{P}<0,01)$ aos resultados obtidos pelo método da coleta total de fezes (tratamento padrão), pelo teste de Dunnett. Os 
tratamentos que mais se aproximaram do resultado esperado foram o Cromo + ICP-OES e La + ED-XRF, com uma diferença de aproximadamente $3 \%$ em relação ao tratamento padrão.

Em relação à taxa de passagem, não houve diferença significativa ( $P>0,01)$ entre os dois métodos de determinação (Taxa de Passagem I e II). Entretanto, a taxa de passagem do cromo foi superior à do lantânio e itérbio, provavelmente em decorrência da menor taxa de passagem do milho em relação à ração. Outros estudos precisam ser realizados para obter mais informações a respeito da taxa de passagem do alimento em suínos e dos marcadores mais adequados a serem utilizados em sua determinação.

Diversos fatores podem influenciar os resultados de digestibilidade aparente obtidos pelo método da coleta parcial de fezes, tais como marcador utilizado, técnica analítica, concentração do marcador na ração, período de adaptação do marcador no trato digestivo dos animais e porcentagem de recuperação dos marcadores nas fezes. Tais fatores necessitam ser melhor investigados, a fim de propor adequações na metodologia de determinação da digestibilidade aparente pelo método da coleta parcial de fezes. 


\title{
Use of different markers for determining apparent digestibility and rate of passage in swine
}

\author{
Author: LILIANA LOTUFO OETTING
}

\author{
Adviser: Prof. Dr. ADIBE LUIZ ABDALLA
}

\section{SUMMARY}

The aim of this work was (1) to evaluate the use of chromic oxide, lanthanum and ytterbium as indigestible markers for the measurement of apparent digestibility in finishing pigs, (2) to determine the rate of passage of feed and (3) to compare two analytical techniques (ICP-OES and ED-XRF).

In the digestibility assay, 12 finishing gilts was used. The treatments represent the combination of the two analytical techniques (ICP-OES and ED-XRF) with the three markers used in the grab collection $\left(\mathrm{Cr}_{2} \mathrm{O}_{3}, \mathrm{La}, \mathrm{Yb}\right)$, and a standard treatment (total collection).

Four animals had been used to compare the single dose and withdrawal methods for measuring the rate of passage. Three markers (chromic oxide, lanthanum and ytterbium) with two analytical techniques were used. The rate of marker disappearance, or the slopes of the equations of the linear regression equations ("b"), was used to compare the rate of passage within treatments.

Comparing the marker method to the classical method (total collection), lower digestibility coefficients $(\mathrm{P}<0,01)$ were obtained, ranging from 3 percents for Chromium + ICP-OES and Lanthanum + ED-XRF until 6 to 10 percents from the other treatments. 
The rate of markers passage, determined using rate constants ("b"), was similar for the withdrawal and single dose methods. However, the rate of passage of chromic oxide was higher than lanthanum and ytterbium, indicating that feed, probably, had a faster rate of passage than maize.

Future research is necessary to draw a more accurately comparison of the three markers used in this study, and also, to consider adaptations to the methodology of grab collection, mainly regarding the inclusion of markers in the diet and adaptation period of the markers in the digestive tract of the animals. 


\section{INTRODUÇÃO}

A produtividade dos animais e a eficiência econômica dos empreendimentos agropecuários estão diretamente relacionadas com a nutrição e a avaliação nutritiva das dietas fornecidas aos animais, tanto qualitativa como quantitativamente.

A determinação dos valores de digestibilidade de nutrientes específicos e/ou de rações experimentais é comumente realizada por meio de ensaios nutricionais, através do uso de gaiolas metabólicas que permitem o controle individual do alimento consumido e o total de fezes excretado. Entretanto, por este ser um método bastante oneroso, surgiram novas metodologias que permitem estimar a digestibilidade dos nutrientes através de métodos indiretos, com o uso de marcadores dietéticos, que reduzem os custos e o período de experimentação.

O marcador mais utilizado em ensaios de digestibilidade com suínos é o óxido crômico, que apresenta o inconveniente de ser um marcador considerado tóxico ao meio ambiente e apresentar grande variação na porcentagem de recuperação nas fezes.

Com a introdução de modernas técnicas analíticas cada vez mais sensíveis, novas propostas para as determinações e novos marcadores têm sido avaliadas. Um grupo de elementos cada vez mais pesquisado como marcador de digesta é o de terras raras: lantânio, itérbio e disprósio.

A confiabilidade de um marcador pode ser avaliada em ensaios de digestibilidade, através da comparação dos resultados obtidos pelo método da coleta total com o método da coleta parcial de fezes. Também é possível comparar o comportamento dos marcadores no trato digestivo dos animais em experimentos de taxa de passagem, utilizando diferentes marcadores simultaneamente. 


\subsection{Objetivo}

O presente projeto de pesquisa visa a avaliação e comparação de três marcadores dietéticos (óxido crômico, lantânio e itérbio) e duas técnicas analíticas (ICPOES e ED-XRF) em experimentos de digestibilidade e taxa de passagem do alimento em suínos. 


\section{REVISÃO DE LITERATURA}

\subsection{Marcadores dietéticos}

Marcador é uma substância presente no alimento (marcador interno) ou adicionada ao alimento (marcador externo), cuja análise de sua concentração no alimento e nas fezes permite calcular os coeficientes de digestibilidade de um nutriente e/ou dieta (Andrigueto et al., 1988). Além dos ensaios de digestibilidade, os marcadores também são comumente utilizados na determinação da taxa de passagem de um determinado alimento ou dieta.

Os marcadores externos podem ser adicionados à ração ou ministrados via oral aos animais (Schneider \& Flatt, 1975). Para que um elemento possa ser utilizado como marcador, deve obedecer as seguintes especificações: ser indigerível e inassimilável pelo organismo, não possuir ação fármaco-dinâmica sobre o trato digestivo, misturar-se uniformemente com a digesta e ser facilmente determinado analiticamente (Andrigueto et al., 1988).

A adoção do método do marcador externo pode apresentar uma problemática em relação às grandes quantidades administradas para a obtenção de resultados analíticos adequados (Uden et al., 1980) e divergências quanto aos resultados de pesquisas, principalmente devido às variabilidades analíticas encontradas (Kozloski et al., 1998; Uden et al., 1980). Uma vez que os coeficientes de digestibilidade são determinados pela relação entre a porcentagem de marcador encontrada na dieta e nas fezes, qualquer equívoco na determinação do marcador, especialmente na dieta, acarreta uma grande discrepância no cálculo final do coeficiente de digestibilidade (Saha \& Gilbreath, 1991). 
O óxido crômico é o marcador externo mais utilizado em ensaios de digestibilidade com suínos (McCarthy et al., 1977; Andrigueto et al., 1988; Saha \& Gilbreath, 1991; Young et al., 1991; Titgemeyer, 1997; Kavanagh et al., 2001). Entretanto, existem algumas divergências a respeito dos métodos analíticos utilizados para sua determinação (Whitby \& Lang, 1960; Kotb \& Luckey, 1972; Saha \& Gilbreath, 1991) e com relação à poluição ambiental, por ser considerado um elemento ambientalmente tóxico (Whitby \& Lang, 1960; Kozloski et al., 1998).

Um indicativo importante da confiabilidade de um marcador é sua porcentagem de recuperação nas fezes (Jagger et al., 1992), sendo que para o óxido crômico esse valor é muito variado (Yin et al., 2000b). Alguns trabalhos encontraram uma alta porcentagem de recuperação do óxido crômico nas fezes (Kavanagh et al., 2001; Bakker \& Jongbloed, 1994) e outros, uma baixa porcentagem de recuperação (Kohler et al., 1990; Moughan et al., 1991; Jagger et al., 1992; Mroz et al., 1996; Yin et al., 2000b).

Embora o elevado número de trabalhos existentes na literatura sugira que o óxido crômico seja um marcador eficiente, as evidências disponíveis sobre sua eficácia ainda não são totalmente conclusivas (Kavanagh et al., 2001), e diferentes marcadores têm sido cada vez mais estudados (McCarthy et al., 1974 e 1977; Moughan et al., 1991; Souza et al., 1998; Yin et al., 2000a; Yin et al., 2000b; Kavanagh et al., 2001).

Os elementos que têm sido muito pesquisados como marcadores da digesta para ruminantes são as terras raras: lantânio, itérbio e disprósio. (Pond et al., 1985; Siddons et al., 1985; Satter et al., 1986; Brandyberry et al., 1991; Poore et al., 1991; Moore, et al., 1992; Manbrini \& Peyraud, 1997; Nogueira et al., 1997; Ryssen \& Mavibela, 1999; Bernard \& Doreau, 2000). Em suínos também são encontrados alguns trabalhos com de taxa de passagem (Holzgraefe et al., 1985; Pond et al., 1986; Imbeah \& Sauer, 1991; Leterne et al., 1991; Imbeah et al., 1995). Entretanto, pouco se conhece a respeito do uso de terras raras como marcadores dietéticos em experimentos de digestibilidade com suínos.

As principais características de interesse das terras raras, para serem utilizadas como marcadores, são a baixa abundância natural e características físico- 
químicas apropriadas (Ulusoy \& Whitley, 1999). De acordo com Satter et al. (1986), as terras raras podem oferecer algumas vantagens em relação ao óxido crômico em termos de sensibilidade e precisão das técnicas analíticas utilizadas, além de apresentarem alta porcentagem de recuperação nas fezes, por não serem absorvidas no trato digestivo dos animais (Kay et al., 1980).

\subsection{Digestibilidade}

A avaliação do valor nutritivo de um alimento para suínos é geralmente realizada por meio de ensaios nutricionais, através da determinação dos coeficientes de digestibilidade dos nutrientes de uma ração ou alimento.

Teoricamente, a determinação do total de proteína e/ou energia ingerida e excretada nas fezes fornece um valor preciso de digestibilidade, expressando o real aproveitamento do nutriente pelo animal. Entretanto, em decorrência de secreções endógenas, tais como secreções biliares, enzimáticas e descamações celulares, somente uma parte da proteína ou gordura encontrada nas fezes é proveniente do alimento testado (Young et al., 1991). Por isso, a determinação da digestibilidade de um nutriente sem considerar essas perdas endógenas é denominada digestibilidade aparente (Young et al., 1991).

A metodologia clássica para determinação da digestibilidade aparente de um nutriente pressupõe o alojamento dos animais em gaiolas metabólicas, que permitem o controle individual do total de alimento ingerido e excretado durante todo período experimental; este método é denominado método direto ou coleta total de fezes.

Contudo, a digestibilidade também pode ser determinada através do uso de marcadores dietéticos, sem a necessidade de quantificar o total de ração consumida e fezes produzidas (Young et al., 1991). Esse método, denominado método indireto ou coleta parcial de fezes, baseia-se no fornecimento de uma quantidade conhecida de marcador na dieta e posterior quantificação desse marcador nas fezes dos animais.

Para avaliar a confiabilidade dos marcadores utilizados na técnica da coleta parcial de fezes pode-se comparar os resultados obtidos com os resultados 
provenientes da coleta total de fezes, que é considerado um método padrão (Baker \& Jongbloed, 1994; Souza et al., 1998; Kavanagh et al., 2001).

\subsection{Taxa de passagem}

A taxa de passagem do alimento pode ser definida como a quantidade de nutriente que atravessa um segmento do trato digestivo em um determinado tempo (Kotb \& Luckey, 1972); sendo outra maneira de comparar o comportamento de diferentes marcadores dietéticos no trato digestivo dos animais.

Para se determinar a taxa de passagem de uma dieta ou alimento adiciona-se certa quantidade de marcador(es) na ração dos animais e, pela mensuração da concentração desse(s) marcador(es) nas fezes após a interrupção do fornecimento na ração ou após o fornecimento de uma dose única na dieta, tem-se a curva de excreção dos marcadores nas fezes com o tempo (Imbeah et al., 1995). A partir desses valores, faz-se análise de regressão para obter uma equação que expresse a relação existente entre a concentração do(s) marcador(es) nas fezes e o tempo (Imbeah et al., 1995).

São poucos os trabalhos encontrados na literatura sobre a determinação da taxa de passagem dos alimentos e/ou dietas em suínos; entre eles: Castle \& Castle (1957), Seerley et al. (1962); Keys \& DeBarthe (1974), Furuya et al. (1978), Kass et al. (1980), Ehle et al. (1982), Holzgraefe et al. (1985), Pond et al. (1986), Varel et al. (1988), Imbeah \& Sauer (1991), Leterne et al. (1991), Imbeah et al. (1995).

De acordo com Nogueira et al. (1997), múltiplos marcadores podem ser utilizados simultaneamente no mesmo animal para se determinar diferentes taxas de passagem. Entretanto, é necessário utilizar técnicas analíticas adequadas que permitam a detecção simultânea desses marcadores nas amostras obtidas.

\subsection{Técnicas analíticas}

Existem diversas técnicas analíticas disponíveis para quantificar o teor de marcador presente nas amostras de fezes e ração. Uma técnica comumente utilizada é a 
espectrofotometria de absorção atômica (Saha \& Gilbreath, 1991; Baker \& Jongbloed, 1994; Mroz et al., 1996; Kavanagh et al., 2001). Entretanto, com a introdução de modernas técnicas analíticas, cada vez mais sensíveis, novas propostas para as determinações têm sido avaliadas (Siddons et al., 1985; Nogueira et al., 1997; Lima et al., 1998).

Em experimentos de múltiplos marcadores, o uso de técnicas analíticas alternativas, que permitem a detecção de diferentes marcadores simultaneamente na mesma amostras, justifica-se pela praticidade e velocidade de emissão dos resultados.

Algumas das técnicas analíticas que correspondem às características desejadas incluem o espectrômetro de emissão ótica com plasma de argônio induzido (ICP-OES) e a técnica nuclear de fluorescência de raios X por dispersão de energia (ED$\mathrm{XRF})$.

O ICP-OES é uma técnica com grande potencial na determinação de terras raras por apresentar uma alta sensibilidade analítica (Satter et al., 1986). Além de apresentar elevada velocidade de emissão de resultados e resposta linear em uma ampla faixa de concentrações.

O ED-XRF é uma técnica não destrutiva e permite a análise rápida de vários elementos simultaneamente, tendo elevado potencial de aplicação em diversas áreas. Entre as características da fluorescência de raios $\mathrm{X}$ pode-se citar: (a) adaptabilidade para automação; (b) análise rápida multielementar; (c) preparação simplificada das amostras; e (d) limite de detectabilidade dentro do exigido por muitas amostras biológicas (Nascimento Filho, 2002). 


\section{MATERIAL E MÉTODOS}

\subsection{Ensaios}

Um ensaio de digestibilidade, utilizando duas metodologias simultaneamente (coleta total e coleta parcial de fezes), e dois experimentos de taxa de passagem (com diferentes curvas de excreção dos marcadores nas fezes) foram realizados no período de 1 a 19 de junho de 2001 (Figura 1).

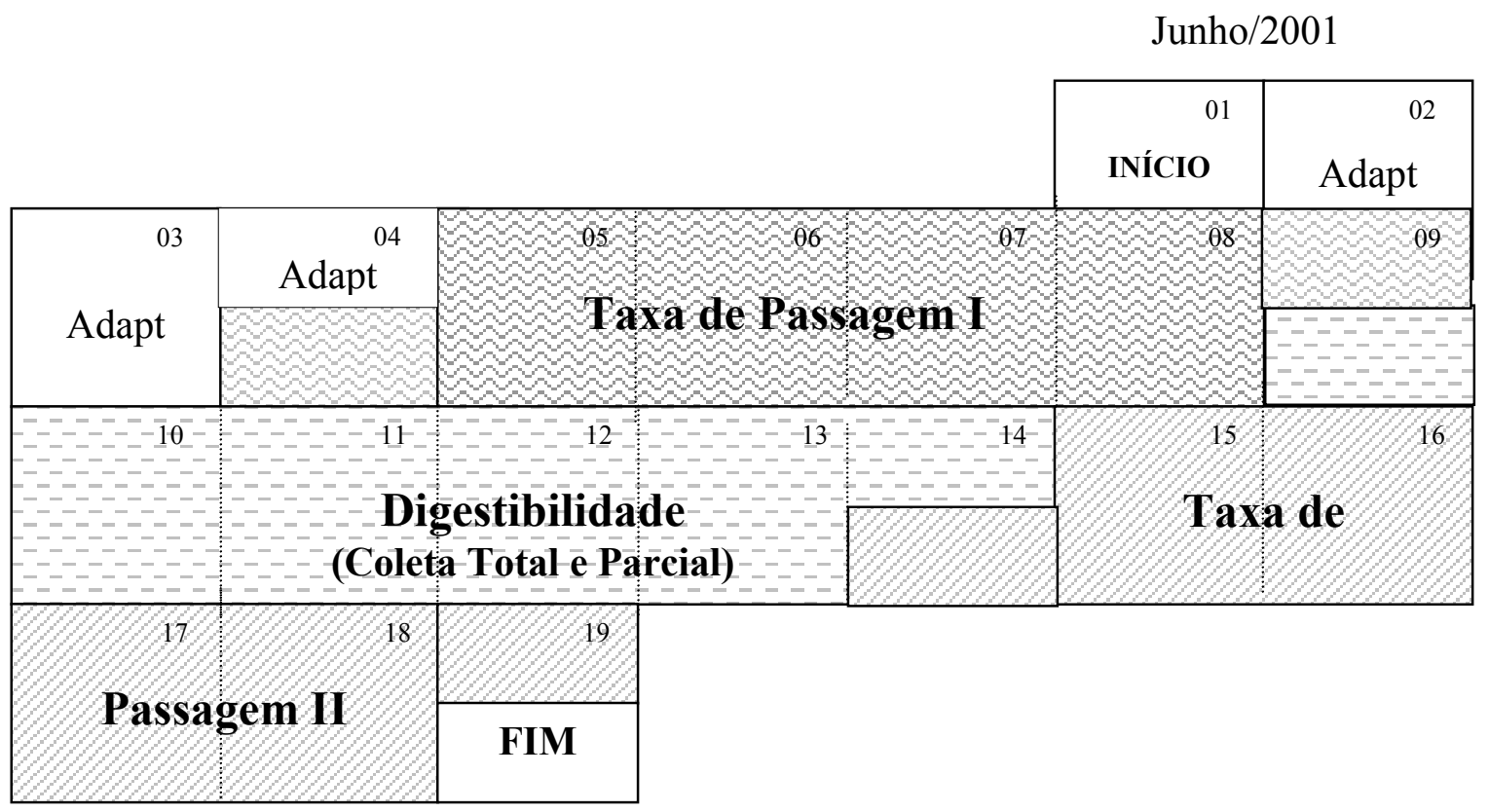

Figura 1 - Cronograma de execução dos dois experimentos de Taxa de Passagem (I e II) e do Ensaio de Digestibilidade 


\subsection{Local e animais}

Os experimentos foram conduzidos no biotério do Laboratório de Nutrição Animal do Centro de Energia Nuclear na Agricultura (CENA), pertencente à Universidade de São Paulo, localizado em Piracicaba/SP.

Foram utilizadas 12 fêmeas suínas Seghers, com idade inicial e final de 133 e 152 dias, respectivamente. A quantidade de animais utilizada variou de acordo com o experimento: 12 animais para o ensaio de digestibilidade e quatro animais para cada experimento de taxa de passagem.

Os animais e a ração utilizada nos experimentos foram cedidos temporariamente pelo Setor de Suinocultura do Departamento de Produção Animal da Escola Superior de Agricultura "Luiz de Queiroz” (ESALQ/USP).

\subsection{Ração experimental}

Durante o período experimental, as fêmeas receberam a mesma dieta basal que consumiam anteriormente no Setor de Suinocultura da ESALQ. Essa ração teve apenas a função de atender as exigências dos animais, não havendo interesse no efeito nutricional da mesma. A formulação da ração encontra-se na Tabela 1 .

A ração experimental fornecida aos animais foi composta pela ração basal acrescida de diferentes marcadores externos (óxido crômico, lantânio e itérbio) simultaneamente. Os animais receberam as mesmas quantidades de cada marcador na dieta, sendo $0,3 \%$ de óxido crômico (correspondente a 0,20 \% de cromo), $60 \mathrm{mg} / \mathrm{kg}$ de lantânio (óxido de lantânio) e $60 \mathrm{mg} / \mathrm{kg}$ de itérbio (cloreto de itérbio). 
Tabela 1. Composição percentual da dieta basal utilizada nos ensaios de digestibilidade e taxa de passagem com suínos em terminação, com os respectivos valores de energia bruta (EB), matéria seca (MS) e proteína bruta (PB) obtidos na análise bromatológica

\begin{tabular}{|c|c|}
\hline Ingredientes & Composição (\%) \\
\hline Milho & 78,0 \\
\hline Farelo de soja & 19,0 \\
\hline Fosfato bicálcico & 1,5 \\
\hline Calcário & 1,0 \\
\hline Premix mineral & 0,1 \\
\hline Premix vitamínico & 0,1 \\
\hline Sal & 0,5 \\
\hline \multicolumn{2}{|l|}{ Análise bromatológica } \\
\hline EB (kcal/kg) & 3568 \\
\hline MS (\%) & 88,0 \\
\hline PB (\%) & 14,4 \\
\hline
\end{tabular}

\subsection{Adição dos marcadores}

Como na literatura não existiam dados suficientes para determinar qual a melhor forma de adição das terras raras na dieta de suínos, foram utilizadas duas metodologias para incorporação do lantânio $(\mathrm{La})$ e do itérbio $(\mathrm{Yb})$ na ração dos animais.

Metade da quantidade total de cada marcador $(30 \mathrm{mg} / \mathrm{kg}$ de $\mathrm{La}$ e 30 $\mathrm{mg} / \mathrm{kg}$ de $\mathrm{Yb}$ ) foi adicionada segundo método descrito por Moore \& Swingle (1987). Neste método, os marcadores foram solubilizados em $6 \mathrm{~L}$ de água destilada, com auxílio de ácido nítrico. Em seguida o $\mathrm{pH}$ da solução foi ajustado para 5,5 e 3,6 kg de milho moído foram adicionados a essa solução e deixados em repouso por $24 \mathrm{~h}$. Após esse período, o milho foi levado à estufa de ventilação forçada a $50^{\circ} \mathrm{C}$ por $48 \mathrm{~h}$. Ao sair da estufa, o milho, marcado com $\mathrm{La}$ e $\mathrm{Yb}$, foi moído em peneira de $3 \mathrm{~mm}$ e adicionado à ração. 
$\mathrm{O}$ óxido crômico e os outros $30 \mathrm{mg} / \mathrm{kg}$ de $\mathrm{La}$ e $\mathrm{Yb}$ foram adicionados diretamente na ração. Procedeu-se uma pré-mistura dos marcadores em uma pequena quantidade de milho, através de um misturador horizontal em "Y", antes de incorporálos e homogeneizá-los ao restante da dieta.

\subsection{Ensaio de digestibilidade}

Durante o Ensaio de Digestibilidade foram utilizadas duas metodologias concomitantemente: a de coleta total e a de coleta parcial de fezes. O cronograma de execução dessas duas metodologias pode ser visualizado na Figura 2.

\begin{tabular}{|c|c|c|c|c|c|c|}
\hline ADAPT & ADAPT & ADAPT & $\mathrm{CP}$ & $\mathrm{CP}$ & $\mathrm{CP}$ & \\
\hline $\begin{array}{c}\mathrm{CR} \\
\mathrm{Fe}_{2} \mathbf{O}_{3}\end{array}$ & $\mathrm{CR}$ & $\begin{array}{l}\text { CR } \\
\text { CT }\end{array}$ & $\begin{array}{l}\mathrm{CR} \\
\mathbf{C T}\end{array}$ & $\begin{array}{l}\text { CR } \\
\text { CT }\end{array}$ & $\begin{array}{c}\mathrm{Fe}_{2} \mathrm{O}_{3} \\
\mathrm{CT}\end{array}$ & CT \\
\hline $1^{\mathrm{o}}$ & $2^{o}$ & $3^{\circ}$ & $4^{o}$ & $5^{\circ}$ & $6^{0}$ & $7^{\circ}$ \\
\hline
\end{tabular}

Coleta Total de Fezes $=$ inclusão de óxido férrico na ração $\left(\mathrm{Fe}_{2} \mathrm{O}_{3}\right), 5$ dias de controle do consumo de ração $(\mathrm{CR})$ e 5 dias de coleta total de fezes (CT)

$\underline{\text { Coleta Parcial de Fezes }}=3$ dias de adaptação dos marcadores no trato digestivo dos animais (ADAPT) e 3 dias de coleta parcial de fezes (CP)

Figura 2 - Cronograma de execução do Ensaio de Digestibilidade utilizando as duas metodologias (coleta total e coleta parcial de fezes) simultaneamente

Foram utilizados 12 animais e os tratamentos envolvidos representam a combinação de duas técnicas analíticas com os três marcadores utilizados na coleta parcial de fezes, e um tratamento padrão (coleta total de fezes). Os tratamentos correspondentes foram: 
(1) Padrão - Coleta total de fezes

(2) Cromo + ICP-OES

(3) Cromo + ED-XRF

(4) Lantânio + ICP-OES

(5) Lantânio + ED-XRF

(6) Itérbio + ICP-OES

(7) Itérbio + ED-XRF

Os animais foram alojados em gaiolas metabólicas e passaram por um período de oito dias de adaptação às gaiolas e medição do consumo voluntário de ração.

A partir do consumo médio de ração na fase de adaptação, obteve-se a quantidade de ração fornecida durante os dias de coleta de fezes de acordo com os seguintes cálculos:

$$
\mathrm{CRR}=\mathrm{I} x \text { Peso metabólico }
$$

onde:

$\mathrm{CRR}=$ Consumo restrito de ração $(\mathrm{kg})$

$\mathrm{I}=$ Índice $=$ Consumo de ração médio dos 8 dias $(\mathrm{kg}) /$ Peso metabólico Peso metabólico $(\mathrm{kg})=(\text { Peso vivo })^{0,75}$

O índice I foi calculado para todos os animais, mas foi adotado o menor valor de I encontrado para o cálculo do CRR. Apesar de haver a padronização do valor de I, o CRR foi determinado individualmente, sendo calculado também em função do peso de cada animal, como ilustrado na Tabela 2. Os valores calculados na Tabela referem-se à quantidade de ração fornecida aos animais por refeição (manhã ou tarde). 
Tabela 2. Cálculo do consumo restrito de ração para o Ensaio de Digestibilidade, a partir do peso metabólico dos suínos

\begin{tabular}{cccccc}
\hline Animal & $\begin{array}{c}\text { Peso vivo } \\
(\mathrm{kg})\end{array}$ & $\begin{array}{c}\text { Peso } \\
\text { metabólico }^{\text {a }}\end{array}$ & $\begin{array}{c}\text { Consumo de } \\
\text { ração }(\mathrm{kg})\end{array}$ & Índice $^{\mathrm{b}}$ & $\begin{array}{c}\text { Consumo }^{\mathrm{c}} \\
\text { restrito }^{\mathrm{c}}(\mathrm{kg})\end{array}$ \\
\hline 1 & 80,0 & 26,74 & 0,945 & 0,035 & 0,945 \\
2 & 76,9 & 25,96 & 1,131 & 0,043 & 0,915 \\
3 & 82,9 & 24,47 & 1,140 & 0,046 & 0,865 \\
4 & 82,5 & 27,37 & 1,265 & 0,016 & 0,965 \\
5 & 71,8 & 24,66 & 1,142 & 0,046 & 0,870 \\
6 & 76,6 & 25,89 & 1,121 & 0,046 & 0,915 \\
7 & 77,0 & 25,99 & 0,946 & 0,036 & 0,920 \\
8 & 90,0 & 29,22 & 1,054 & 0,036 & 1,030 \\
9 & 86,7 & 28,41 & 1,234 & 0,043 & 1,005 \\
10 & 83,8 & 27,69 & 1,201 & 0,043 & 0,980 \\
11 & 80,1 & 26,77 & 1,094 & 0,040 & 0,945 \\
12 & 92,1 & 29,72 & 1,280 & 0,043 & 1,050 \\
\hline
\end{tabular}

${ }^{a}$ Peso metabólico $=$ peso vivo ${ }^{0,7}$

${ }^{\mathrm{b}}$ Índice $=$ consumo / peso metabólico

${ }^{\mathrm{c}}$ Consumo restrito $=$ peso metabólico $\mathrm{X}$ menor índice

Para padronizar o consumo e minimizar as sobras, a ração ficou disponível ao animal por 30 minutos e foi fornecida duas vezes ao dia, das 7:30 às 8:00h e das 16:30 às 17:00h. Após esse período, a ração foi retirada do comedouro para efetuar a pesagem das sobras.

Como a água foi fornecida no próprio comedouro, a mesma foi retirada antes do fornecimento da ração e recolocada após o recolhimento das sobras. Para garantir água ad libitum aos animais completou-se o volume de água do comedouro/bebedouro no decorrer dia quando necessário.

Foram feitas amostragens da ração e pesagem das sobras diariamente. 


\subsubsection{Coleta total de fezes}

O método da coleta total de fezes compreendeu um período de cinco dias de controle do consumo de ração e coleta total de fezes, utilizando o óxido férrico (na concentração de $2 \%$ na ração) como um indicador do início e do final do período de coleta (Figura 2). O óxido férrico é utilizado para identificar as fezes dos animais que são realmente provenientes da ração que se deseja avaliar.

As fezes produzidas foram quantificadas duas vezes ao dia, de manhã e à tarde, retirando-se amostras diárias de aproximadamente $150 \mathrm{~g}$, que foram imediatamente acondicionadas em sacos plásticos e congeladas para posterior análise laboratorial. $\mathrm{O}$ cálculo do coeficiente de digestibilidade (CD) para o método da coleta total de fezes foi feito de acordo com a seguinte equação:

$\mathrm{CD}(\%)=100 \times$ Quantidade de nutriente na ração - Quantidade de nutriente nas fezes Quantidade de nutriente na ração

\subsubsection{Coleta parcial de fezes}

Antes de dar início aos três dias de coleta parcial de fezes, os animais passaram por um período de três dias de adaptação e manutenção do fluxo dos marcadores no trato digestivo (Figura 2).

Foram coletadas amostras de fezes diretamente do reto dos animais, duas vezes ao dia (manhã e tarde), as quais foram imediatamente acondicionadas em sacos plásticos transparentes e congeladas. O cálculo dos coeficientes de digestibilidade pela técnica da coleta parcial de fezes foi feito de acordo com a equação:

$$
\mathrm{CD}(\%)=100-100 \times \frac{(\% \text { marcador na ração })}{(\% \text { marcador nas fezes })} \times \frac{(\% \text { nutriente nas fezes })}{(\% \text { nutriente na ração })}
$$




\subsection{Taxa de passagem}

A taxa de passagem dos animais foi determinada através de dois ensaios, com diferentes curvas de excreção dos marcadores nas fezes (Taxa de Passagem I curva "crescente" e Taxa de Passagem II - curva decrescente). Como não estava muito bem esclarecida na literatura a quantidade de lantânio e itérbio que deveria ser adicionada na dieta, optou-se por utilizar diferentes quantidades desses marcadores nos ensaios de taxa de passagem $(30 \mathrm{mg} / \mathrm{kg}$ de La e Yb para a Taxa de Passagem I e 60 $\mathrm{mg} / \mathrm{kg}$ para a Taxa de Passagem II) para verificar se $30 \mathrm{mg} / \mathrm{kg}$ era suficiente para ser detectado pelas duas técnicas analíticas.

Foram utilizados quatro animais e foram feitas coletas de fezes em intervalos regulares pré-estabelecidos para cada um dos ensaios. Os tratamentos correspondentes foram:

(1) Cromo + ICP-OES

(2) Cromo + ED-XRF

(3) Lantânio + ICP-OES

(4) Lantânio + ED-XRF

(5) Itérbio + ICP-OES

(6) Itérbio + ED-XRF

Para comparar as curvas obtidas em cada tratamento foi necessário transformá-las em curvas lineares, através da conversão da concentração dos marcadores nas fezes em seus logaritmos naturais (ln). Efetuou-se então uma análise de regressão para cada tratamento, a partir do ln da concentração máxima de marcador encontrada nas fezes até a estabilidade da curva (concentração $=0$ ), estabelecendo a relação existente entre o ln da concentração dos marcadores nas fezes e o tempo, segundo a equação:

$$
\mathrm{Y}_{\ln }=\mathrm{a}+\mathrm{b.t}
$$


onde "Yln" é o logaritmo natural da concentração do marcador no tempo "t", "a" é o logaritmo natural da concentração do marcador no tempo " $t=0$ " e " $b$ " é a inclinação da curva de regressão, sendo o logaritmo natural da taxa de desaparecimento do marcador (Imbeah et al., 1995).

A comparação entre os tratamentos e os dois métodos de obtenção da curva foi realizada através do valor de " $b$ " das equações obtidas.

\subsubsection{Taxa de passagem I}

Neste método, a ração contendo todos os marcadores foi fornecida em dose única aos animais, obtendo-se uma curva "crescente" de saída dos marcadores nas fezes com o tempo.

A ração contendo os marcadores foi fornecida de maneira restrita, de acordo com o peso metabólico e o consumo dos animais (Tabela 3), para garantir a ingestão dos marcadores em uma única refeição.

Tabela 3. Cálculo do consumo restrito de ração para a Taxa de Passagem I, a partir do peso metabólico dos suínos

\begin{tabular}{|c|c|c|c|c|c|}
\hline Animal & $\begin{array}{c}\text { Peso vivo } \\
(\mathrm{kg})\end{array}$ & $\begin{array}{c}\text { Peso } \\
\text { metabólico }^{\mathrm{a}}\end{array}$ & $\begin{array}{l}\text { Consumo de } \\
\text { ração }(\mathrm{kg})\end{array}$ & Índice ${ }^{b}$ & $\begin{array}{c}\text { Consumo } \\
\text { restrito }^{c}(\mathrm{~kg})\end{array}$ \\
\hline 9 & 86,7 & 28,41 & 1,147 & 0,040 & 0,995 \\
\hline 10 & 83,8 & 27,69 & 1,045 & 0,037 & 0,970 \\
\hline 11 & 80,1 & 26,77 & 1,092 & 0,040 & 0,940 \\
\hline 12 & 92,1 & 29,72 & 1,050 & 0,035 & 1,040 \\
\hline
\end{tabular}

${ }^{a}$ Peso metabólico $=$ peso vivo ${ }^{0,75}$

${ }^{\mathrm{b}}$ Índice $=$ consumo $/$ peso metabólico

${ }^{\mathrm{c}}$ Consumo restrito $=$ peso metabólico $\mathrm{X}$ menor índice

As coletas foram feitas direto do reto dos animais, a partir do exato momento em que foi administrada a ração contendo os marcadores (tempo $=0 \mathrm{~h}$ ) e, consecutivamente, de 4 em 4 horas nos dois primeiros dias, $6 \mathrm{~h}$ em $6 \mathrm{~h}$ no terceiro e 
quarto dia, e de $8 \mathrm{~h}$ em $8 \mathrm{~h}$ no quinto dia, compreendendo um total de 21 amostras por animal, em cinco dias de coleta de fezes.

As amostras de fezes coletadas foram embaladas em sacos plásticos individuais para cada animal e horário de coleta e congeladas para posterior análise.

\subsubsection{Taxa de passagem II}

Nesta taxa de passagem, os animais receberam a ração restrita (Tabela 4) contendo todos os marcadores durante cinco dias, para adaptação dos marcadores no trato digestivo dos animais.

Tabela 4. Cálculo do consumo restrito de ração para a Taxa de Passagem II, a partir do peso metabólico dos suínos

\begin{tabular}{cccccc}
\hline Animal & $\begin{array}{c}\text { Peso vivo } \\
(\mathrm{kg})\end{array}$ & $\begin{array}{c}\text { Peso } \\
\text { metabólico }^{\mathrm{a}}\end{array}$ & $\begin{array}{c}\text { Consumo de } \\
\text { ração }(\mathrm{kg})\end{array}$ & Índice $^{\mathrm{b}}$ & $\begin{array}{c}\text { Consumo }^{\mathrm{c}} \\
\text { restrito }^{\mathrm{c}}(\mathrm{kg})\end{array}$ \\
\hline 2 & 76,9 & 25,96 & 1,131 & 0,043 & 0,915 \\
3 & 82,9 & 24,47 & 1,140 & 0,046 & 0,865 \\
4 & 82,5 & 27,37 & 1,265 & 0,016 & 0,965 \\
8 & 90,0 & 29,22 & 1,054 & 0,036 & 1,030 \\
\hline
\end{tabular}

${ }^{a}$ Peso metabólico $=$ peso vivo ${ }^{0,75}$

${ }^{\mathrm{b}}$ Índice $=$ consumo $/$ peso metabólico

${ }^{\mathrm{c}}$ Consumo restrito $=$ peso metabólico $\mathrm{X}$ menor índice

As coletas tiveram início após a interrupção do fornecimento dos marcadores na dieta $(\mathrm{t}=0 \mathrm{~h})$, obtendo-se uma curva decrescente de saída dos marcadores nas fezes com o tempo. A partir desse momento, os animais passaram a consumir ração (sem marcador) à vontade e foram feitas coletas periódicas de 4 em 4 horas nas primeiras 24 horas, $6 \mathrm{~h}$ em $6 \mathrm{~h}$ nas 24 horas seguintes, $8 \mathrm{~h}$ em $8 \mathrm{~h}$ nas 48 horas seguintes e 12 em 12 horas nas últimas coletas, compreendendo um total de 17 amostras por animal, em cinco dias de coleta de fezes.

As amostras de fezes coletadas foram embaladas em sacos plásticos individuais para cada animal e horário de coleta e congeladas para posterior análise. 


\subsection{Análises laboratoriais}

As amostras de fezes foram descongeladas, sendo que as amostras do ensaio de digestibilidade foram homogeneizadas em uma única amostra composta (Abdalla et al, 1999). Estas amostras foram secas em bandejas apropriadas, em estufa de circulação forçada de ar a $65^{\circ} \mathrm{C}$ durante 72 horas. Posteriormente, as amostras de fezes e a ração experimental foram moídas em moinho tipo Willey, em peneira crivada de $1 \mathrm{~mm}$ de diâmetro, e submetidas à análise bromatológica e análise dos marcadores.

As determinações de matéria seca e proteína bruta foram realizadas de acordo com a Association of Official Analytical Chemists (Aoac, 1995). Para a análise de energia bruta utilizou-se Bomba Calorimétrica modelo PARR 1261. Todas as amostras foram analisadas em duplicata.

A análise dos marcadores por ICP-OES foi realizada na Embrapa Pecuária Sudeste, em São Carlos, através do espectrômetro de emissão ótica com plasma de argônio induzido de configuração radial VISTA RL ICP-OES (Varian, Mulgrave, Austrália). Os parâmetros operacionais do equipamento encontram-se na Tabela 5.

Antes de proceder a determinação, as amostras foram pesadas $(250 \mathrm{mg})$ em tubos de ensaio e submetidas a uma digestão nitro-perclórica. Foram adicionados 4 $\mathrm{mL}$ de ácido nítrico e $2 \mathrm{~mL}$ de ácido perclórico em cada tubo de ensaio, permanecendo em temperatura ambiente por aproximadamente $12 \mathrm{~h}$. Após esse período, os tubos foram levados ao bloco digestor, onde a temperatura foi elevada gradativamente até atingir $210^{\circ} \mathrm{C}$. As amostras foram retiradas do bloco digestor quando apresentaram coloração amarelada e um terço do volume inicial. Terminada a digestão, completou-se o volume para $25 \mathrm{~mL}$. 
Tabela 5. Parâmetros operacionais utilizados no ICP-OES para análise de cromo, lantânio e itérbio em amostras de ração e fezes de suínos

\begin{tabular}{lc}
\hline \multicolumn{1}{c}{ Parâmetros operacionais } & Especificações \\
\hline Potência de rádio-frequência $(\mathrm{kW})$ & 1,3 \\
Vazão do gás de plasma (L/min) & 15,0 \\
Vazão do gás auxiliar (L/min) & 1,5 \\
Vazão do gás nebulizador (L/min) & 0,8 \\
Altura de observação (mm) & 9,0 \\
Sistema de introdução da amostra & Câmara de nebulização "Sturman Masters" e \\
Comprimento de onda (nm) & nebulizador "V-groove" \\
& Cr 205,562 \\
& La 333,749 \\
& Yb 369,408 \\
\hline
\end{tabular}

A análise dos marcadores através da técnica analítica nuclear de fluorescência de raios $\mathrm{X}$ por dispersão de energia (ED-XRF) foi realizada no Laboratório de Instrumentação Nuclear do CENA/USP. As amostras foram pesadas (1g) em invólucros apropriados e levadas diretamente para análise, sem passar por nenhum tipo de pré-tratamento. As concentrações de cada marcador foram determinadas pela área do pico formado na emissão dos raios $\mathrm{X}$ característicos de cada elemento analisado $(\mathrm{Cr}$, La e $\mathrm{Yb}$ ) após excitação com tubo de raios $\mathrm{X}$ com alvo de molibdênio e filtro de zircônio (raios X de 17,44 kev), e calculando-se posteriormente as concentrações finais por meio de equações matemáticas. Entretanto, para análise do La, foi necessário utilizar uma fonte de Am-241 (1Ci), emissor de raios gama de 59,5 kev, aumentando a sensibilidade analítica em 12 vezes, para anular a interferência que o ferro havia exercido na detecção do La quando se utilizou o tubo de raios $\mathrm{X}$ como fonte de excitação. As amostras de fezes foram medidas por 100 segundos e as amostras de ração por 1000 segundos. 


\subsection{Análise estatística}

\subsubsection{Ensaio de digestibilidade}

Foram analisados sete tratamentos em cada um dos 12 animais, gerando 84 observações experimentais para essa etapa. A unidade experimental correspondeu ao próprio animal. O modelo estatístico correspondente foi o seguinte:

$$
\begin{gathered}
y_{i j}=\mu+t_{i}+a_{j}+\varepsilon_{i j} ; \\
i=1,2, \ldots, 7 \quad \text { e } \quad j=1,2, \ldots, 12
\end{gathered}
$$

Onde:

$$
\begin{aligned}
& Y_{\mathrm{ij}}=\text { coeficiente de digestibilidade do nutriente } \\
& \mu=\text { média geral referente a todas observações } \\
& \mathrm{t}_{\mathrm{i}}=\text { efeito do i-ésimo tratamento } \\
& \mathrm{a}_{\mathrm{j}}=\text { efeito do j-ésimo animal } \\
& \varepsilon_{\mathrm{ij}}=\text { erro aleatório }
\end{aligned}
$$

Os dados foram analisados por meio da análise de variância do PROC GLM (General Linear Models) do SAS (Statistical Analysis System, 2000).

Foi feita a comparação de médias, confrontando o tratamento controle com os demais, utilizando o Teste de Dunnett a 1\% de probabilidade.

\subsubsection{Taxa de passagem}

Foi feita uma análise de regressão para cada tratamento (seis tratamentos) e cada animal (4 animais), gerando um total de 24 equações lineares de regressão (PROC REG - SAS, 2000). O modelo estatístico correspondente foi o seguinte: 


$$
\begin{gathered}
y_{i j}=\mu+t_{i}+a_{j}+\varepsilon_{i j} ; \\
i=1,2, \ldots, 6 \quad j=1,2,3 \text { e } 4
\end{gathered}
$$

Onde:

$$
\begin{aligned}
& Y_{\mathrm{ij}}=\text { inclinação da curva de regressão linear } \\
& \mu=\text { média geral referente a todas observações } \\
& \mathrm{t}_{\mathrm{i}}=\text { efeito do i-ésimo tratamento } \\
& \mathrm{a}_{\mathrm{j}}=\text { efeito do j-ésimo animal } \\
& \varepsilon_{\mathrm{ij}}=\text { erro aleatório }
\end{aligned}
$$

Posteriormente, as inclinações das retas ("b") foram comparadas através do teste de Tukey a 1\% de significância. 


\section{RESULTADOS E DISCUSSÃO}

\subsection{Digestibilidade}

\subsubsection{Coleta total de fezes}

A análise bromatológica das amostras de fezes dos doze animais encontrase na Tabela 6.

Tabela 6. Análise de energia bruta (EB), matéria seca (MS) e proteína bruta (PB) das fezes obtidas no ensaio de digestibilidade com suínos em terminação

\begin{tabular}{cccc}
\hline Animal & EB $(\mathrm{kcal} / \mathrm{kg})$ & $\mathrm{MS}^{\mathrm{a}}(\%)$ & $\mathrm{PB}(\%)$ \\
\hline 1 & 4054 & 96,44 & 19,39 \\
2 & 4158 & 96,10 & 18,28 \\
3 & 4043 & 95,58 & 18,91 \\
4 & 3992 & 96,39 & 18,60 \\
5 & 4054 & 96,33 & 19,43 \\
6 & 4053 & 96,54 & 18,62 \\
7 & 4193 & 95,99 & 19,87 \\
8 & 3946 & 96,15 & 16,51 \\
9 & 4067 & 95,87 & 18,37 \\
10 & 4010 & 96,13 & 18,34 \\
11 & 4119 & 96,39 & 19,62 \\
12 & 4057 & 95,89 & 18,01 \\
\hline Média & 4062 & 96,14 & 18,66 \\
\hline CV $^{\mathrm{b}}(\%)$ & 1,68 & 0,30 & 4,83 \\
\hline Valos & & & \\
\hline
\end{tabular}

${ }^{\mathrm{a}}$ Valores de materia seca após a pré-secagem das amostras

${ }^{\mathrm{b}}$ Coeficiente de variação 
A partir da quantificação da ração consumida e das fezes excretadas (Tabela 7) durante os cinco dias de coleta, calculou-se os valores de digestibilidade aparente da energia bruta, matéria seca e proteína bruta para o método da coleta total de fezes (Tabela 8).

Tabela 7. Consumo total de ração e produção total de fezes, com valores expressos em matérias seca (MS), durante os cinco dias de coleta de fezes do ensaio de digestibilidade com suínos

\begin{tabular}{ccccc}
\hline Animal & $\begin{array}{c}\text { Consumo total } \\
\text { de ração } \\
(\mathrm{kg})\end{array}$ & $\begin{array}{c}\text { Consumo total } \\
\text { de ração }^{\text {a }} \\
(\mathrm{kg} \mathrm{MS})\end{array}$ & $\begin{array}{c}\text { Produção total } \\
\text { de fezes } \\
(\mathrm{kg})\end{array}$ & $\begin{array}{c}\text { Produção total } \\
\text { de fezes }^{\mathrm{b}} \\
(\mathrm{kg} \mathrm{MS})\end{array}$ \\
\hline 1 & 9,42 & 8,28 & 2,43 & 0,73 \\
2 & 9,15 & 8,05 & 3,21 & 0,97 \\
4 & 8,65 & 7,61 & 2,78 & 0,85 \\
5 & 9,65 & 8,49 & 2,79 & 0,84 \\
6 & 8,70 & 7,66 & 2,30 & 0,69 \\
7 & 9,15 & 8,05 & 3,12 & 0,94 \\
8 & 7,80 & 6,86 & 2,63 & 0,80 \\
9 & 10,17 & 8,95 & 2,85 & 0,86 \\
10 & 10,01 & 8,81 & 2,39 & 0,73 \\
11 & 9,68 & 8,51 & 2,76 & 0,84 \\
12 & 9,31 & 8,19 & 2,59 & 0,78 \\
\hline Média & 10,34 & 9,09 & 3,14 & 0,96 \\
\hline CV ${ }^{\mathrm{c}}$ (\%) & 9,33 & 8,21 & 2,85 & 0,83 \\
\hline${ }^{\mathrm{a}}$ Consumo total de ração $=$ Consumo total x \% MS na ração & & 10,91 \\
${ }^{\mathrm{b}}$ Produção total de fezes = Produção de fezes x \% de MS das fezes & \\
${ }^{\mathrm{c}}$ Coeficiente de variação & & & \\
\hline
\end{tabular}


Tabela 8. Coeficientes de digestibilidade aparente da energia bruta (CD-EB), matéria seca (CD-MS) e proteína bruta (CD-PB) de suínos em terminação obtidos pelo método da coleta total de fezes

\begin{tabular}{cccc}
\hline Animal & CD-EB (\%) & CD-MS (\%) & CD-PB (\%) \\
\hline 1 & 88,93 & 91,11 & 86,94 \\
2 & 84,55 & 87,86 & 83,24 \\
3 & 86,16 & 88,76 & 84,03 \\
4 & 87,83 & 90,07 & 86,01 \\
5 & 88,66 & 90,88 & 86,60 \\
6 & 85,43 & 88,31 & 83,49 \\
7 & 85,03 & 88,32 & 82,51 \\
8 & 88,30 & 90,32 & 87,93 \\
9 & 89,68 & 91,69 & 88,50 \\
10 & 87,89 & 90,14 & 86,34 \\
11 & 87,88 & 90,41 & 85,76 \\
12 & 86,91 & 89,44 & 85,67 \\
\hline Média & 87,27 & 89,77 & 85,59 \\
\hline CV $(\%)$ & 1,89 & 1,37 & 2,21 \\
\hline
\end{tabular}

${ }^{a}$ Coeficiente de variação

Os coeficientes de digestibilidade encontrados pelo método da coleta total de fezes coincidem com os dados existentes na literatura. Neves (1991) e Oliveira (1999) encontraram coeficientes de digestibilidade da matéria seca, energia bruta e proteína bruta para suínos em terminação, recebendo ração farelada à base de milho e farelo de soja, variando de 85 a $90 \%$.

\subsubsection{Coleta parcial de fezes}

Para calcular os coeficientes de digestibilidade aparente pelo método da coleta parcial de fezes foram utilizadas as médias das concentrações de cada marcador (três repetições por amostra) na ração (Tabela 9) e a concentração dos marcadores nas fezes (Tabela 10), obtidas pelas duas técnicas analíticas (ICP-OES e ED-XRF). 
Tabela 9. Concentração dos três marcadores (cromo, lantânio e itérbio) na ração experimental obtida pelas duas técnicas analíticas (ICP-OES e ED-XRF)

\begin{tabular}{|c|c|c|c|c|c|c|}
\hline \multirow{2}{*}{ Ração } & \multicolumn{3}{|c|}{ ICP-OES } & \multicolumn{3}{|c|}{ ED-XRF } \\
\hline & Cromo & Lantânio & Itérbio & Cromo & Lantânio & Itérbio \\
\hline Amostra 1 & 0,20 & 103 & 70 & 0,21 & 70 & 51 \\
\hline Amostra 2 & 0,19 & 77 & 66 & 0,23 & 60 & 54 \\
\hline Amostra 3 & 0,17 & 93 & 62 & 0,23 & 51 & 63 \\
\hline Média & 0,19 & 91 & 66 & 0,22 & 61 & 56 \\
\hline Conc. esperada $^{a}$ & 0,20 & 60 & 60 & 0,20 & 60 & 60 \\
\hline \% Rec. na ração ${ }^{b}$ & 95 & 151 & 110 & 110 & 101 & 93 \\
\hline $\mathrm{CV}^{\mathrm{c}}(\%)$ & 6,70 & 14,40 & 5,67 & 6,30 & 16,18 & 11,30 \\
\hline \multicolumn{7}{|c|}{${ }^{\mathrm{a}}$ Concentração esperada na ração $($ Cromo $=\%$; La e $\mathrm{Yb}=\mathrm{mg} / \mathrm{kg})$} \\
\hline $\begin{array}{l}{ }^{\mathrm{b}} \text { Porcentagem de rect } \\
{ }^{\mathrm{c}} \text { Coeficiente de varia }\end{array}$ & ação na & $=\frac{\text { (quanti }}{\text { (quant }}$ & $\frac{\text { encont }}{\text { espera }}$ & 100 & Gilbrea & \\
\hline
\end{tabular}

Tabela 10. Concentração de cada marcador (cromo, lantânio e itérbio) nas fezes dos 12 animais obtida através de duas técnicas analíticas (ICP-OES e ED-XRF)

\begin{tabular}{|c|c|c|c|c|c|c|}
\hline \multirow[b]{2}{*}{ Animal } & \multicolumn{3}{|c|}{ ICP-OES } & \multicolumn{3}{|c|}{ ED-XRF } \\
\hline & $\begin{array}{c}\text { Cromo } \\
(\%)\end{array}$ & $\begin{array}{c}\text { Lantânio } \\
(\mathrm{mg} / \mathrm{kg})\end{array}$ & $\begin{array}{c}\text { Itérbio } \\
(\mathrm{mg} / \mathrm{kg})\end{array}$ & $\begin{array}{c}\text { Cromo } \\
(\%)\end{array}$ & $\begin{array}{c}\text { Lantânio } \\
(\mathrm{mg} / \mathrm{kg})\end{array}$ & $\begin{array}{c}\text { Itérbio } \\
(\mathrm{mg} / \mathrm{kg})\end{array}$ \\
\hline 1 & 1,613 & 626 & 372 & 1,397 & 524 & 369 \\
\hline 2 & 1,642 & 657 & 396 & 1,379 & 549 & 454 \\
\hline 3 & 1,712 & 627 & 405 & 1,431 & 594 & 434 \\
\hline 4 & 1,684 & 676 & 399 & 1,341 & 528 & 409 \\
\hline 5 & 1,687 & 660 & 398 & 1,383 & 569 & 356 \\
\hline 6 & 1,766 & 640 & 421 & 1,421 & 533 & 456 \\
\hline 7 & 1,610 & 594 & 370 & 1,355 & 521 & 438 \\
\hline 8 & 1,550 & 642 & 363 & 1,274 & 483 & 360 \\
\hline 9 & 1,710 & 641 & 410 & 1,357 & 532 & 417 \\
\hline 10 & 1,685 & 629 & 380 & 1,283 & 502 & 417 \\
\hline 11 & 1,801 & 658 & 423 & 1,510 & 573 & 465 \\
\hline 12 & 1,644 & 619 & 397 & 1,286 & 505 & 397 \\
\hline Média & 1,675 & 639 & 394 & 1,368 & 534 & 414 \\
\hline $\mathrm{CV}^{\mathrm{a}}(\%)$ & 4,14 & 3,45 & 4,96 & 5,02 & 6,00 & 9,04 \\
\hline
\end{tabular}

${ }^{\mathrm{a}}$ Coeficiente de variação 
Pode-se observar (Tabela 9) que existe diferença entre as técnicas analíticas utilizadas, pois a determinação da concentração dos marcadores pelas duas técnicas resultou em concentrações diferentes de cada marcador na ração $(0,19 \times 0,22 \%$ de cromo; 91 x $61 \mathrm{mg} / \mathrm{kg}$ de lantânio e 66 x 56 mg/kg de itérbio para o ICP-OES e EDXRF, respectivamente). Nota-se também que existe variação entre as repetições de uma mesma amostra de ração, evidenciada pelos coeficientes de variação encontrados $(5,67$ a $16,18 \%)$.

A porcentagem de recuperação dos marcadores na ração, determinada pela relação entre a quantidade de marcador encontrada e a esperada, variou de 93 a $151 \%$, de acordo com o marcador e a técnica analítica utilizada. A porcentagem média de recuperação do cromo obtida por Kavanagh et al. (2001) foi de $93 \%$, sendo inferior à obtida neste experimento (102\%). Variações entre as porcentagens de recuperação dos marcadores na ração também foram reportadas por Saha \& Gilbreath (1991), estando entre 96 e $106 \%$. Tais diferenças podem ser explicadas pela dificuldade na amostragem da ração, fazendo com que a quantidade analisada subestime ou superestime a real quantidade adicionada (Kavanagh et al., 2001).

A partir da relação entre a concentração de marcador analisada na ração e nas fezes (Tabelas 9 e 10) foram calculados os coeficientes de digestibilidade aparente da energia bruta, matéria seca e proteína bruta (Tabelas 11, 12 e 13, respectivamente) para o cromo, lantânio e itérbio analisados tanto por ICP-OES quanto por ED-XRF. 
Tabela 11. Coeficientes de digestibilidade da energia bruta (\%) dos 12 animais, obtidos para cada marcador analisado por ICP-OES e ED-XRF

\begin{tabular}{ccccccc}
\hline \multirow{2}{*}{ Animal } & \multicolumn{3}{c}{ ICP-OES } & & \multicolumn{3}{c}{ ED-XRF } \\
\cline { 2 - 7 } & Cromo & Lantânio & Itérbio & Cromo & Lantânio & Itérbio \\
\hline 1 & 83,93 & 80,17 & 75,79 & 78,51 & 84,16 & 79,10 \\
2 & 83,91 & 80,75 & 76,83 & 77,83 & 84,61 & 82,70 \\
3 & 85,16 & 80,60 & 78,22 & 79,45 & 86,31 & 82,58 \\
4 & 84,85 & 81,93 & 77,79 & 77,98 & 84,53 & 81,45 \\
5 & 84,67 & 81,23 & 77,42 & 78,34 & 85,45 & 78,41 \\
6 & 85,29 & 80,56 & 78,56 & 78,83 & 84,40 & 83,07 \\
7 & 83,49 & 78,57 & 75,05 & 77,29 & 83,68 & 81,95 \\
8 & 83,81 & 81,28 & 75,99 & 77,20 & 83,37 & 79,30 \\
9 & 84,97 & 80,79 & 78,22 & 78,07 & 84,55 & 81,67 \\
10 & 84,87 & 80,60 & 76,70 & 77,00 & 83,76 & 81,81 \\
11 & 85,39 & 80,84 & 78,39 & 79,82 & 85,30 & 83,15 \\
12 & 84,39 & 80,15 & 77,54 & 76,90 & 83,75 & 80,78 \\
\hline Média & 84,56 & 80,62 & 77,20 & 78,10 & 84,48 & 81,33 \\
\hline CV ${ }^{\text {a }}(\%)$ & 0,74 & 1,00 & 1,47 & 1,20 & 1,00 & 1,96 \\
\hline${ }^{a}$ Coeficiente de variação & & & & &
\end{tabular}


Tabela 12. Coeficientes de digestibilidade da matéria seca (\%) dos 12 animais, obtidos para cada marcador analisado por ICP-OES e ED-XRF

\begin{tabular}{ccccccc}
\hline \multirow{2}{*}{ Animal } & \multicolumn{3}{c}{ ICP-OES } & & ED-XRF \\
\cline { 2 - 7 } & Cromo & Lantânio & Itérbio & Cromo & Lantânio & Itérbio \\
\hline 1 & 85,85 & 82,54 & 78,69 & 81,09 & 86,06 & 81,60 \\
2 & 86,20 & 83,48 & 80,12 & 80,97 & 86,80 & 85,15 \\
3 & 86,90 & 82,88 & 80,77 & 81,86 & 87,91 & 84,63 \\
4 & 86,46 & 83,85 & 80,15 & 80,32 & 86,17 & 83,42 \\
5 & 86,50 & 83,48 & 80,13 & 80,94 & 87,20 & 81,00 \\
6 & 87,05 & 82,88 & 81,13 & 81,36 & 86,26 & 85,09 \\
7 & 85,95 & 81,77 & 78,77 & 80,68 & 86,12 & 84,64 \\
8 & 85,36 & 83,08 & 78,29 & 79,38 & 84,96 & 81,28 \\
9 & 86,81 & 83,15 & 80,89 & 80,76 & 86,44 & 83,91 \\
10 & 86,54 & 82,73 & 79,27 & 79,53 & 85,55 & 83,82 \\
11 & 87,34 & 83,41 & 81,28 & 82,52 & 87,27 & 85,41 \\
12 & 86,28 & 82,54 & 80,25 & 79,69 & 85,71 & 83,09 \\
\hline Média & 86,43 & 82,98 & 79,97 & 80,75 & 86,37 & 83,58 \\
\hline CV ${ }^{\text {a }}$ (\%) & 0,63 & 0,66 & 1,25 & 1,15 & 0,93 & 1,85 \\
\hline${ }^{a}$ Coeficiente de variação & & & & &
\end{tabular}


Tabela 13. Coeficientes de digestibilidade da proteína bruta (\%) dos 12 animais, obtidos para cada marcador analisado por ICP-OES e ED-XRF

\begin{tabular}{ccccccc}
\hline \multirow{2}{*}{ Animal } & \multicolumn{3}{c}{ ICP-OES } & & \multicolumn{3}{c}{ ED-XRF } \\
\cline { 2 - 6 } & Cromo & Lantânio & Itérbio & Cromo & Lantânio & Itérbio \\
\hline 1 & 81,04 & 76,60 & 71,44 & 74,65 & 81,31 & 75,34 \\
2 & 82,56 & 79,12 & 74,88 & 75,95 & 83,31 & 81,23 \\
3 & 82,88 & 77,62 & 74,87 & 76,29 & 84,20 & 79,90 \\
4 & 82,59 & 79,24 & 74,49 & 74,70 & 82,22 & 78,69 \\
5 & 81,88 & 77,81 & 73,31 & 74,40 & 82,81 & 74,48 \\
6 & 83,33 & 77,97 & 75,71 & 76,01 & 82,32 & 80,82 \\
7 & 80,71 & 74,96 & 70,85 & 73,47 & 80,93 & 78,90 \\
8 & 83,29 & 80,68 & 75,22 & 76,47 & 82,83 & 78,64 \\
9 & 83,26 & 78,61 & 75,74 & 75,57 & 82,79 & 79,58 \\
10 & 82,93 & 78,11 & 73,72 & 74,05 & 81,68 & 79,48 \\
11 & 82,84 & 77,49 & 74,61 & 76,29 & 82,73 & 80,21 \\
12 & 82,92 & 78,27 & 75,42 & 74,72 & 82,21 & 78,96 \\
\hline Média & 82,51 & 78,04 & 74,18 & 75,21 & 82,44 & 78,55 \\
\hline CV ${ }^{\text {a }}$ (\%) & 1,04 & 1,80 & 2,15 & 1,32 & 1,06 & 2,56 \\
\hline${ }^{\text {a }}$ Coeficiente de variação & & & & &
\end{tabular}

\subsubsection{Comparação entre a coleta total e parcial de fezes}

Foram comparados os coeficientes de digestibilidade obtidos pelo método da coleta total de fezes (padrão) com os coeficientes de digestibilidade obtidos pelo método da coleta parcial de fezes para cada marcador, analisado por duas técnicas analíticas, a fim de avaliar qual(is) tratamento(s) apresenta(m) a melhor estimativa da digestibilidade em relação à coleta total de fezes (Tabela 14). 
Tabela 14. Comparação entre as médias dos coeficientes de digestibilidade (CD) da energia bruta (EB), matéria seca (MS) e proteína bruta (PB), obtidas pelo método da coleta total e parcial de fezes utilizando três marcadores $(\mathrm{Cr}$, La e $\mathrm{Yb}$ ) e as duas técnicas analíticas (ICP-OES e ED-XRF)

\begin{tabular}{|c|c|c|c|c|c|c|c|c|}
\hline \multirow{2}{*}{$\begin{array}{l}\text { CD } \\
(\%)\end{array}$} & \multirow{2}{*}{$\begin{array}{c}\text { Coleta } \\
\text { Total }\end{array}$} & \multicolumn{3}{|c|}{ ICP-OES } & \multicolumn{3}{|c|}{ ED-XRF } & \multirow{2}{*}{$\begin{array}{l}\mathrm{CV}^{\mathrm{a}} \\
(\%)\end{array}$} \\
\hline & & Cromo & Lantânio & Itérbio & Cromo & Lantânio & Itérbio & \\
\hline EB & 87,27 & $84,56 *$ & $80,62 *$ & $77,21 *$ & $78,10 *$ & $84,49 *$ & $81,33 *$ & 1,25 \\
\hline MS & 89,77 & $86,44 *$ & $82,98 *$ & $79,98 *$ & $80,76^{*}$ & $86,37 *$ & $83,59 *$ & 1,05 \\
\hline PB & 85,58 & $82,52 *$ & $78,04 *$ & $74,19 *$ & $75,21 *$ & $82,45 *$ & $78,85^{*}$ & 1,48 \\
\hline
\end{tabular}

* Médias diferem do tratamento padrão (coleta total) pelo teste de Dunnet a 1\% de probabilidade

${ }^{\text {a }}$ Coeficente de variação

Os coeficientes de digestibilidade obtidos pelo método da coleta parcial de fezes, independente do marcador utilizado, diferem significativamente $(\mathrm{P}<0,01)$ do tratamento padrão (coleta total) pelo teste de Dunnett. Esses resultados estão de acordo com resultados existentes na literatura, onde o método da coleta parcial de fezes, através do uso de marcadores dietéticos, subestimou a digestibilidade dos nutrientes em relação ao método da coleta total de fezes (McCarthy et al., 1974; Moughan et al., 1991; Mroz et al., 1996). Entretanto, essa diferença não foi observada em outros trabalhos com suínos, utilizando o óxido crômico como marcador dietético (Baker \& Jongbloed, 1994; Moreira et al., 1994, Schiavon, et al., 1996; Kavanagh et al., 2001; Moreira et al., 2001).

Embora nenhum dos tratamentos avaliados tenha sido considerado estatisticamente semelhante ao tratamento padrão, os tratamentos Cromo + ICP-OES e Lantânio + ED-XRF foram os que obtiveram resultados mais próximos do padrão, apresentando uma diferença na estimativa da digestibilidade de aproximadamente $3 \%$ em relação à coleta total de fezes. Os mesmos resultados foram encontrados por McCarthy et al. (1974), Moughan et al. (1991) e Mroz et al. (1996), onde a utilização de óxido crômico gerou coeficientes de digestibilidade 3 a 5 \% inferiores que os obtidos pelo método da coleta total de fezes. 
Os demais tratamentos apresentaram diferenças de aproximadamente 6 a 7 \% (Itérbio + ED-XRF e Lantânio + ICP-OES) e 9 a 10 \% (Cromo + ED-XRF e Itérbio + ICP-OES) em relação ao tratamento padrão. A confiabilidade dos resultados obtidos está assegurada pelos baixos coeficientes de variação encontrados $(1,25,1,05$ e 1,48 \% para a análise de EB, MS e PB, respectivamente).

No trabalho realizado por Moreira et al. (1994), as diferenças entre os coeficientes de digestibilidade do milho, determinados pelo método da coleta total de fezes e pelo óxido crômico, foram de 10,75 \% para a determinação da digestibilidade da proteína bruta e 2,5\% para a energia bruta, contudo não foram encontradas diferenças significativas entre os dois métodos de determinação, possivelmente em decorrência de uma maior variação entre os dados (não apresentada).

A estimativa da digestibilidade pelo método da coleta parcial de fezes está altamente correlacionada com a quantidade de marcador analisada na amostra de ração. Uma pequena variação na determinação do marcador, especialmente na dieta, pode acarretar enorme discrepância no cálculo final dos coeficientes de digestibilidade (Saha \& Gilbreath, 1991). Essa relação ficou evidenciada na Tabela 15, onde foram recalculados os coeficientes de digestibilidade, considerando a quantidade adicionada de marcador na dieta $(0,2 \%$ de cromo e $60 \mathrm{mg} / \mathrm{kg}$ de lantânio e itérbio).

Tabela 15. Comparação entre as médias dos coeficientes de digestibilidade (CD) da energia bruta (EB), matéria seca (MS) e proteína bruta $(\mathrm{PB})$, obtidas pelo método da coleta total e parcial de fezes utilizando três marcadores $(\mathrm{Cr}$, La e $\mathrm{Yb}$ ) e duas técnicas analíticas (ICP-OES e ED-XRF), e considerando a quantidade esperada de marcador na ração

\begin{tabular}{ccccccccc}
\hline \multirow{2}{*}{$\begin{array}{c}\text { CD } \\
(\%)\end{array}$} & Coleta & \multicolumn{3}{c}{ ICP-OES } & \multicolumn{3}{c}{ ED-XRF } & CV $^{\mathrm{a}}$ \\
\cline { 3 - 7 } & Total & Cromo & Lantânio & Itérbio & Cromo & Lantânio & Itérbio & $(\%)$ \\
\hline EB & 87,27 & $83,42 *$ & 87,22 & $79,28 *$ & $79,69 *$ & $84,71 *$ & $80,17 *$ & 1,22 \\
MS & 89,77 & $85,44 *$ & 88,78 & $81,80 *$ & $82,16 *$ & $86,56 *$ & $82,57 *$ & 1,04 \\
PB & 85,59 & $81,23 *$ & 85,52 & $76,53 *$ & $77,02 *$ & $82,69 *$ & $77,54 *$ & 1,44 \\
\hline
\end{tabular}

* Médias diferem do tratamento padrão (coleta total) pelo teste de Dunnet a 1\% de probabilidade

${ }^{\text {a }}$ Coeficente de variação 
Considerando a quantidade esperada de marcador na ração como verdadeira, houve variação nos coeficientes de digestibilidade $(-1 \%$ para $\mathrm{Cr}+\mathrm{ICP}-\mathrm{OES}$, $+1,5 \%$ para $\mathrm{Cr}+\mathrm{ED}-\mathrm{XRF},+6,6 \%$ para La $+\mathrm{ICP}-\mathrm{OES},+0,2 \%$ para $\mathrm{La}+\mathrm{ED}-\mathrm{XRF}$ e $+2 \%$ para $\mathrm{Yb}+\mathrm{ICP}-\mathrm{OES}$ e $-1 \%$ para $\mathrm{Yb}+\mathrm{ED}-\mathrm{XRF}$, aproximadamente).

A maior variação encontrada $(+6,6 \%)$ foi para o Lantânio + ICP-OES que, sob essas condições, não diferiu estatisticamente $(\mathrm{P}<0,01)$ do tratamento padrão, através do teste de Dunnett.

A magnitude dessa diferença é proporcional à porcentagem analisada e a porcentagem esperada de marcador na ração. Para o cromo, uma variação de $0,01 \%$ na ração gerou uma diferença de aproximadamente $1 \%$ na determinação do coeficiente de digestibilidade. Sob esse ponto de vista, os resultados obtidos por Bakker \& Jongbloed (1994) e Kavanagh et al. (2001) poderiam ter apresentado diferenças significativas entre os dois métodos de determinação, pois uma variação na quantidade de marcador na ração aumentaria a diferença entre os coeficientes de digestibilidade obtidos pelos dois métodos, uma vez que em ambos trabalhos a quantidade de marcador analisada na ração foi inferior à quantidade esperada.

A possibilidade de erro analítico da ração não foi descartada por Kavanah et al. (2001), que justificou a menor porcentagem de marcador encontrada por falhas na amostragem, em virtude da variação na granulometria da ração. Embora Baker \& Jongbloed (1994) não tenham discutido essa questão, problemas analíticos na determinação do cromo na ração foram evidenciados pelos coeficientes de variação encontrados em sua determinação, variando de 5,0 a 9,8 \% de acordo com a dieta.

Alguns autores não analisaram a amostra de ração para marcadores (Jagger et al., 1992 e Yin et al., 2000b) e outros (Moreira et al., 1994 e 2001) não explicitaram se foi considerada a quantidade analisada ou esperada de marcador na ração para calcular os coeficientes de digestibilidade. Assumindo a quantidade esperada de marcador como real, exclui-se os erros de homogeneização e amostragem da ração, reduzindo a confiabilidade dos resultados (Kavanagh et al., 2001).

As opiniões são divergentes quanto à concentração de marcador na ração que deve ser utilizada nos cálculos de digestibilidade (valor esperado ou analisado). 
Saha \& Gilbreath (1991) defendem a utilização de um fator de correção como forma de eliminar ou reduzir os erros provenientes da grande variabilidade encontrada na porcentagem de recuperação dos marcadores na ração e nas fezes. Kavanagh et al. (2001) acreditam que a utilização do valor esperado de marcador na ração pode levar a erros na determinação da digestibilidade. Uma das maneiras de solucionar esse problema pode ser através do uso de um número maior de repetições na análise das amostras de ração, até que a variação entre as amostras seja minimizada e a amostra seja realmente representativa de toda ração.

A diferença entre os coeficientes de digestibilidade obtidos pelo método da coleta total de fezes e pela técnica dos marcadores também pode ser explicada pela baixa porcentagem de recuperação dos marcadores nas fezes (Tabela 16).

Tabela 16. Porcentagem de recuperação ${ }^{a}$ dos marcadores nas fezes (analisados por ICP-OES e ED-XRF), considerando a concentração analisada de marcadores na ração

\begin{tabular}{|c|c|c|c|c|c|c|}
\hline & \multicolumn{3}{|c|}{ ICP-OES } & \multicolumn{3}{|c|}{ ED-XRF } \\
\hline & Cromo & Lantânio & Itérbio & Cromo & Lantânio & Itérbio \\
\hline Ração $^{b}$ & 0,19 & 91,03 & 66,22 & 0,22 & 60,86 & 56,56 \\
\hline \multicolumn{7}{|l|}{ Animal } \\
\hline 1 & 67,588 & 56,425 & 46,932 & 51,516 & 69,889 & 56,457 \\
\hline 2 & 94,287 & 81,167 & 68,477 & 69,695 & 100,433 & 57,343 \\
\hline 3 & 91,524 & 72,120 & 65,204 & 67,336 & 101,061 & 51,007 \\
\hline 4 & 78,868 & 68,111 & 56,269 & 55,273 & 78,675 & 42,144 \\
\hline 5 & 72,577 & 61,071 & 51,547 & 52,352 & 77,946 & 33,722 \\
\hline 6 & 97,204 & 75,759 & 69,754 & 68,813 & 93,360 & 55,245 \\
\hline 7 & 89,017 & 70,652 & 61,598 & 65,932 & 91,750 & 53,242 \\
\hline 8 & 70,925 & 63,196 & 50,015 & 51,304 & 70,328 & 36,287 \\
\hline 9 & 67,394 & 54,336 & 48,646 & 47,058 & 66,793 & 36,147 \\
\hline 10 & 78,573 & 63,108 & 53,364 & 52,660 & 74,604 & 42,758 \\
\hline 11 & 81,450 & 63,997 & 57,585 & 60,080 & 82,491 & 46,207 \\
\hline 12 & 82,326 & 66,682 & 59,834 & 56,674 & 80,565 & 43,723 \\
\hline Média & 80,97 & 66,38 & 57,43 & 58,22 & 82,32 & 46,19 \\
\hline $\mathrm{CV}^{\mathrm{c}}(\%)$ & 12,70 & 11,70 & 13,40 & 13,50 & 14,30 & 18,20 \\
\hline \multicolumn{7}{|c|}{ \% Rec. $=\frac{(\text { quantidade de marcador nas fezes em MS x excreção fezes MS })}{\text { (quantidade de marcador na ração em MS x consumo ração MS })} \times 100$} \\
\hline \multicolumn{7}{|c|}{ b Unidades: Cromo (\%); Lantânio e Itérbio (mg/kg) } \\
\hline${ }^{\mathrm{c}}$ Coeficient & ão & & & & & \\
\hline
\end{tabular}


Pode-se perceber (Tabela 16) que os tratamentos com as maiores porcentagens de recuperação (Cromo + ICP-OES e Lantânio + ED-XRF) também apresentaram os coeficientes de digestibilidade mais próximos do tratamento padrão (Tabela 14). Essa relação entre a porcentagem de recuperação de um marcador nas fezes e o coeficiente de digestibilidade pôde ser confirmada na Tabela 17, quando as porcentagens de recuperação dos marcadores nas fezes foram recalculadas com base na quantidade esperada de marcador na ração.

Tabela 17. Comparação entre a porcentagem de recuperação dos marcadores nas fezes (analisados por ICP-OES e ED-XRF) considerando a concentração esperada e a concentração analisada de marcadores na ração

\begin{tabular}{|c|c|c|c|c|c|}
\hline $\begin{array}{l}\text { Técnica } \\
\text { analítica }\end{array}$ & Marcador $^{\mathrm{b}}$ & $\begin{array}{l}\text { Quantidade } \\
\text { esperada }^{\mathrm{b}}\end{array}$ & $\begin{array}{l}\text { Quantidade } \\
\text { encontrada }^{\mathrm{b}}\end{array}$ & $\begin{array}{c}\% \text { Recuperação }{ }^{a} \\
\text { (esperada) }\end{array}$ & $\begin{array}{c}\% \text { Recuperação } \\
\text { (analisada) }\end{array}$ \\
\hline \multirow{3}{*}{ ICP-OES } & Cromo & 0,20 & 0,19 & 76,79 & 80,97 \\
\hline & Lantânio & 60,00 & 91,03 & 99,70 & 66,38 \\
\hline & Itérbio & 60,00 & 66,20 & 61,63 & 57,43 \\
\hline \multirow{3}{*}{ ED-XRF } & Cromo & 0,20 & 0,22 & 62,75 & 58,22 \\
\hline & Lantânio & 60,00 & 60,86 & 83,61 & 82,32 \\
\hline & Itérbio & 60,00 & 56,56 & 65,08 & 46,19 \\
\hline \multicolumn{6}{|c|}{ a $\%$ Rec. $=$ (quantidade de marcador nas fezes em MS x excreção fezes MS) x 100} \\
\hline
\end{tabular}

O Lantânio + ICP-OES foi o único tratamento que apresentou uma porcentagem de recuperação nas fezes próxima de $100 \%(99,7 \%)$, por isso este tratamento não diferiu estatisticamente do tratamento padrão quando os coeficientes de digestibilidade foram estimados a partir da quantidade esperada de marcador na ração (Tabela 15). Por isso, quando os coeficientes de digestibilidade são corrigidos para 100\% de recuperação dos marcadores nas fezes, a diferença entre os métodos de determinação da digestibilidade diminui sensivelmente (Kohler et al., 1990).

A porcentagem de recuperação de um marcador nas fezes pode apresentar resultados variados. Na literatura, foram encontradas porcentagens de recuperação do 
cromo nas fezes de 72 a 106 \% (McCarthy et al., 1974; Kolher et al., 1990; Moughan, 1991; Saha \& Gilbreath, 1991; Mroz et al., 1996; Yin et al., 2000a e 2000b).

De acordo com Schiavon et al. (1996), um dos motivos para essa variação na porcentagem de recuperação nas fezes pode ser o tempo de adaptação do marcador no trato digestivo dos animais. Os autores encontraram um aumento progressivo na porcentagem de recuperação do cromo nas fezes $(90,4,95,2,98,0$ e 100,3 \% de recuperação) com o aumento do período de adaptação $(7,12,23$ e 28 dias de adaptação, respectivamente). A partir de doze dias de adaptação, não foram encontradas diferenças significativas entre os coeficientes de digestibilidade obtidos pelo método da coleta parcial com os da coleta total de fezes.

O período de coleta também pode influenciar a porcentagem de recuperação dos marcadores nas fezes. Embora o aumento do período de coleta de três para dez dias não tenha resultado em diferenças estatísticas entre as porcentagens de recuperação do cromo nas fezes $(\mathrm{P}>0,05)$, houve uma redução de aproximadamente 10 \% no coeficiente de variação (Baker \& Jongbloed, 1994).

Outro fator que pode influenciar a porcentagem de recuperação de um marcador nas fezes é a técnica analítica utilizada e/ou interferência de outros elementos na análise (Saha \& Gilbreath, 1991). Os autores encontraram uma redução de $10 \%$ na porcentagem de recuperação do cromo em rações contendo elevados níveis de cálcio e fósforo, analisando-o por espectrofotometria de absorção atômica.

A baixa porcentagem de recuperação de um marcador nas fezes também pode ser explicada por diversas outras razões: sedimentação do marcador na ração (McCarthy et al., 1974), variação diária na excreção dos marcadores nas fezes, estimativa incorreta da coleta total de fezes (Baker \& Jongbloed, 1994) e possibilidade de retenção e/ou absorção dos marcadores no trato digestivo dos animais (Mroz et al., 1996; Yin et al., 2000b).

Portanto, apesar dos tratamentos Cromo + ICP-OES e Lantânio + EDXRF apresentarem resultados próximos aos da coleta total de fezes, são necessárias mais pesquisas para alcançar resultados conclusivos a respeito dos marcadores mais confiáveis a serem utilizados no método da coleta parcial de fezes. Tais pesquisas 
também devem incluir adaptações na metodologia, principalmente em relação à inclusão dos marcadores na dieta e período de adaptação dos marcadores no trato digestivo dos animais, para que a metodologia da coleta parcial de fezes seja uma estimativa precisa da digestibilidade aparente dos nutrientes.

\subsection{Taxa de passagem}

\subsubsection{Taxa de passagem I}

As Figuras de 3 a 8 trazem as curvas de excreção dos seis tratamentos analisados (Cromo + ICP-OES, Cromo + ED-XRF, Lantânio + ICP-OES, Lantânio + ED-XRF, Itérbio + ICP-OES e Itérbio + ED-XRF) expressos em concentração de marcador nas fezes $(\mathrm{mg} / \mathrm{kg})$ com o tempo (h), após o fornecimento de uma dose única dos marcadores na dieta (2000 mg/kg de cromo e $30 \mathrm{mg} / \mathrm{kg}$ de lantânio e itérbio). 


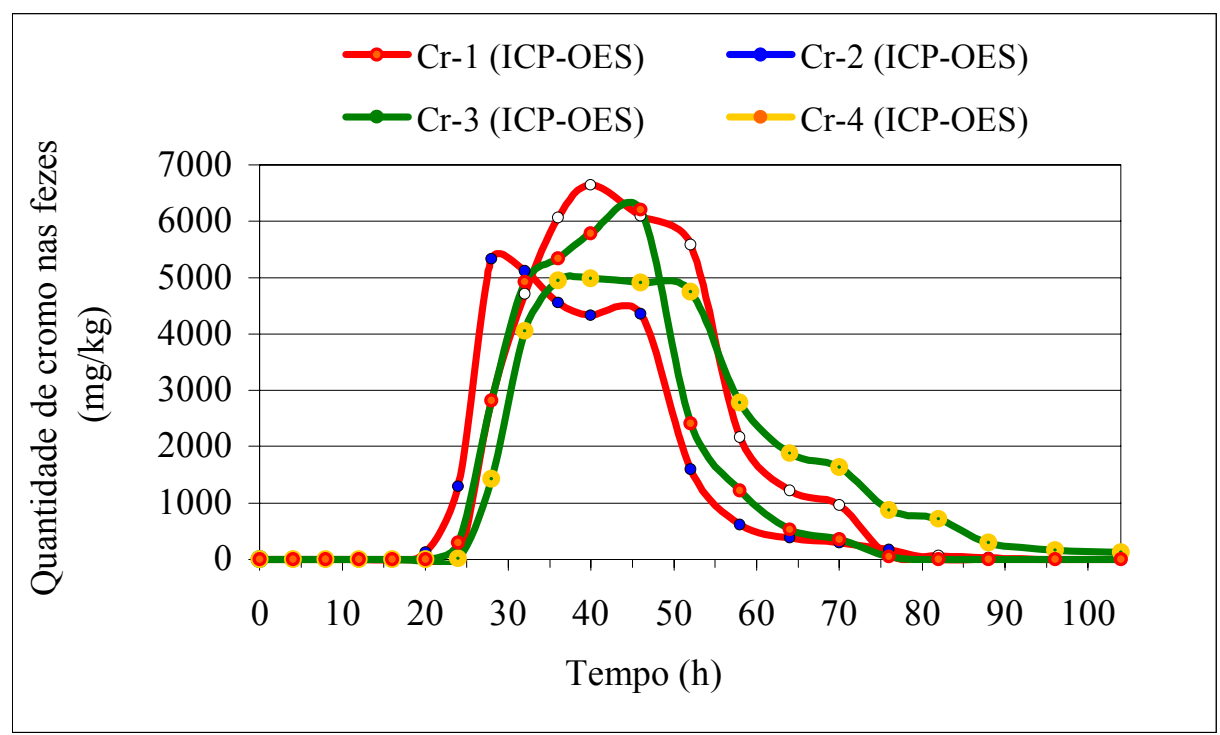

Figura 3 - Curva de excreção do cromo, analisado por ICP-OES, para os quatro animais na Taxa de Passagem I.

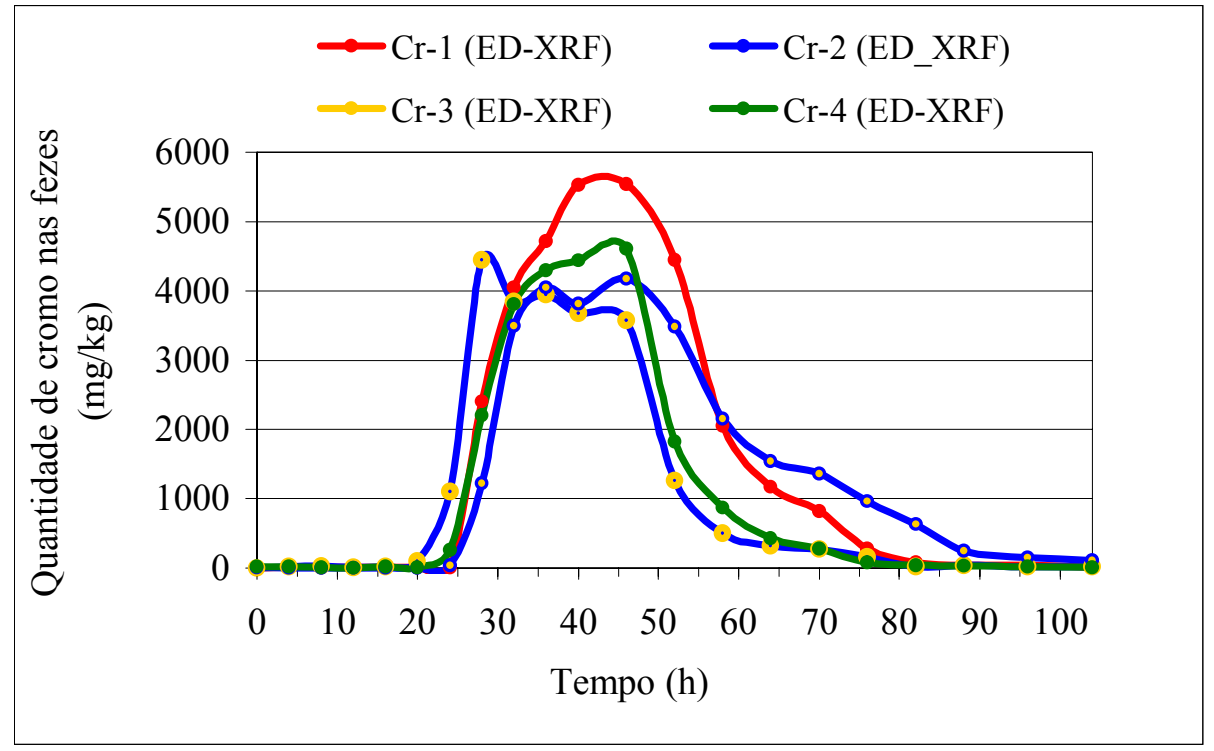

Figura 4 - Curva de excreção do cromo, analisado por ED-XRF, para os quatro animais na Taxa de Passagem I. 


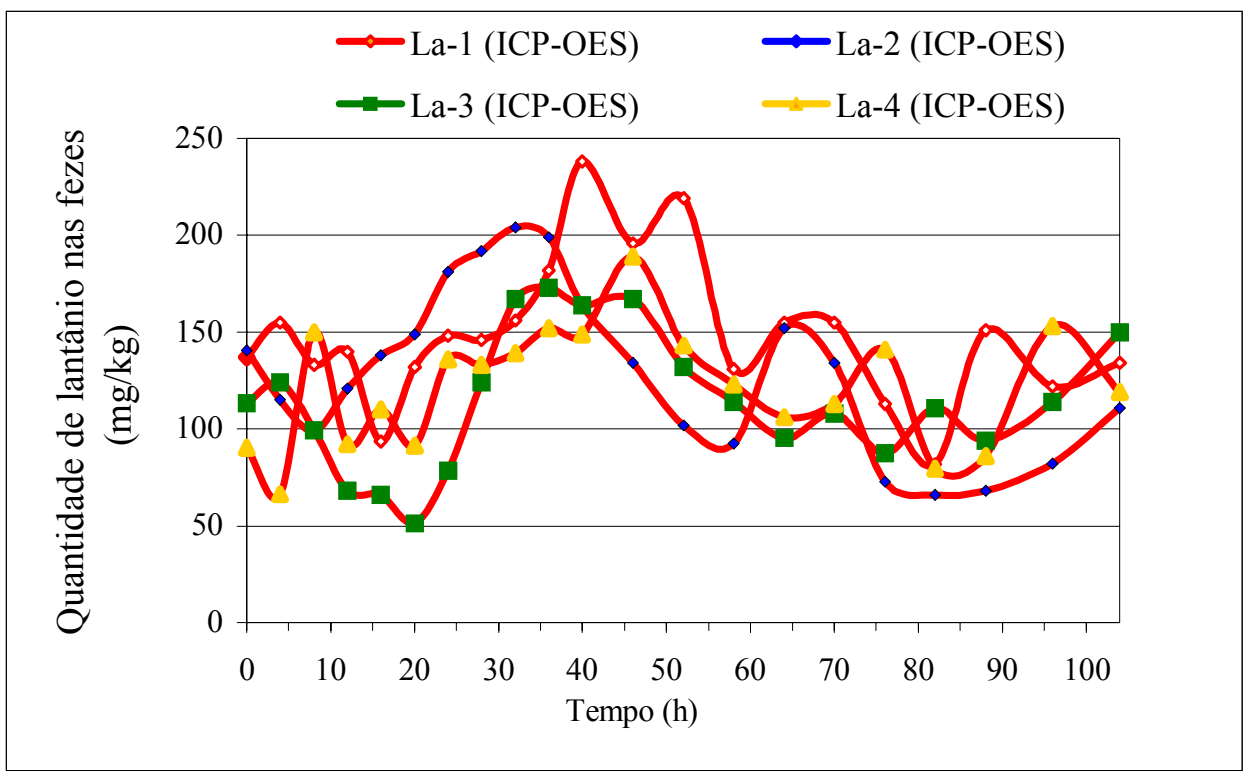

Figura 5 - Curva de excreção do lantânio, analisado por ICP-OES, para os quatro animais na Taxa de Passagem I.

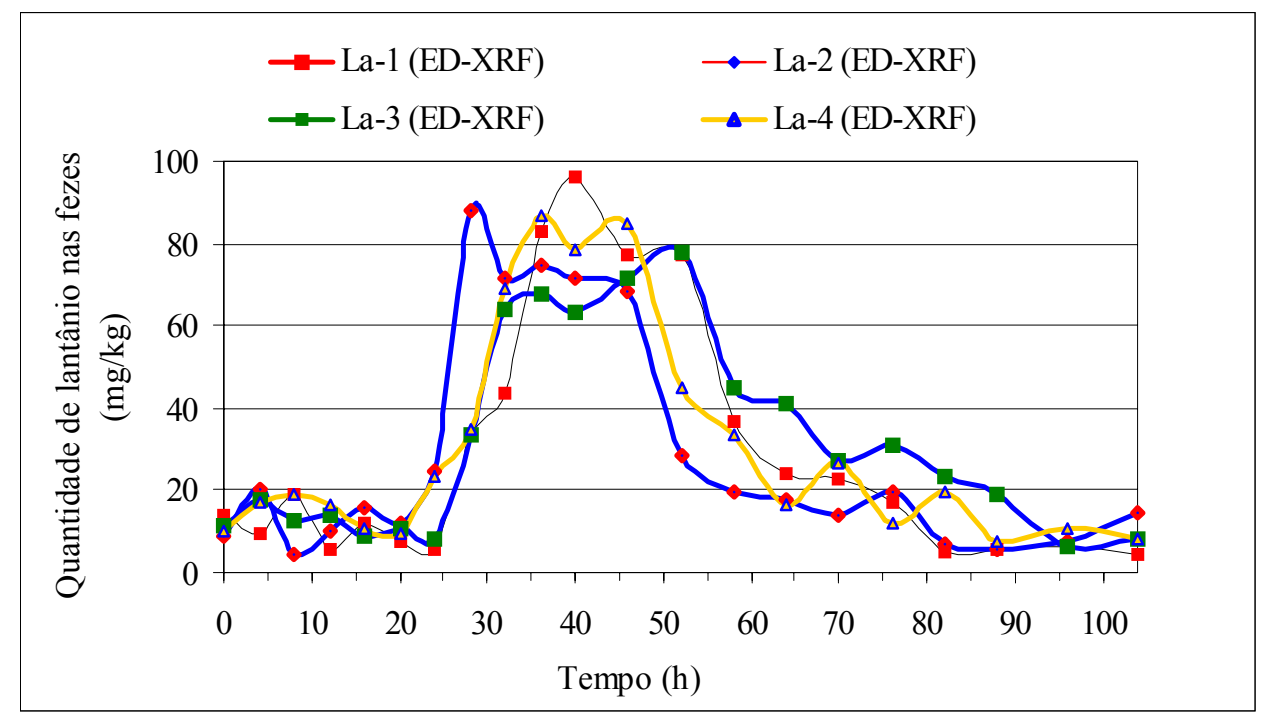

Figura 6 - Curva de excreção do lantânio, analisado por ED-XRF, para os quatro animais na Taxa de Passagem I. 


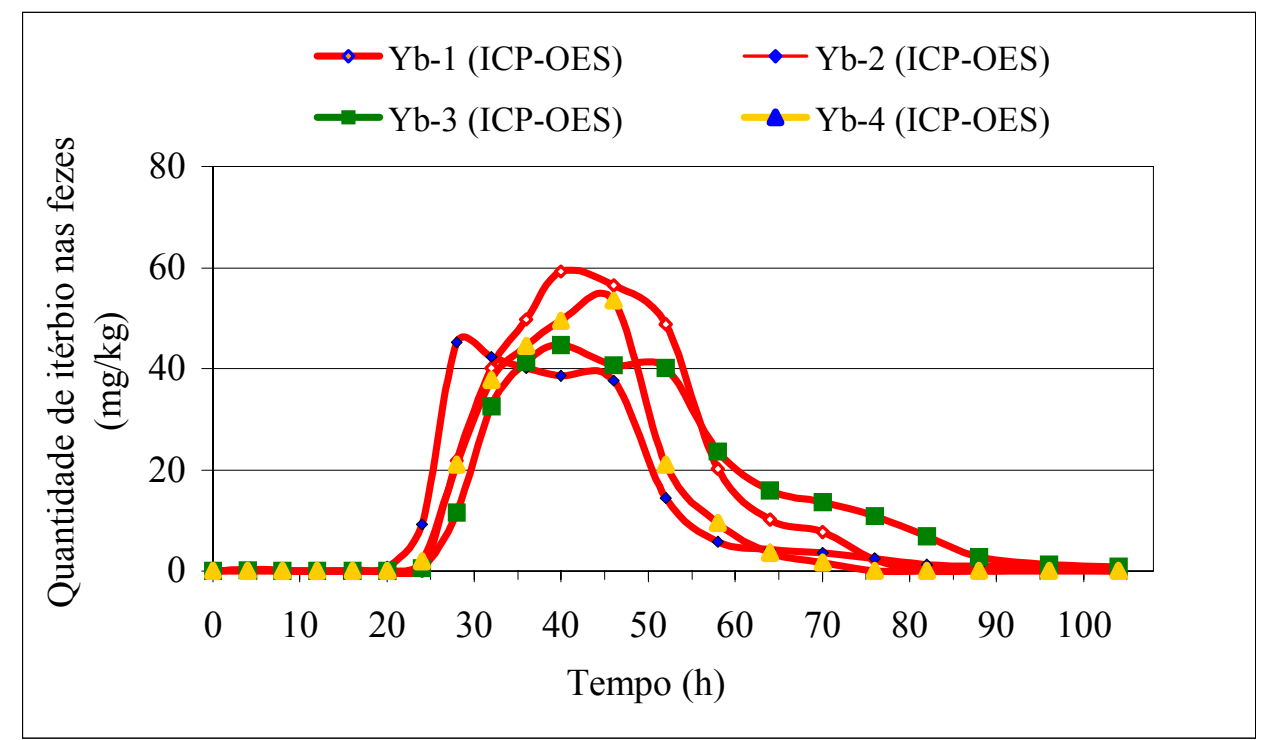

Figura 7 - Curva de excreção do itérbio, analisado por ICP-OES, para os quatro animais na Taxa de Passagem I.

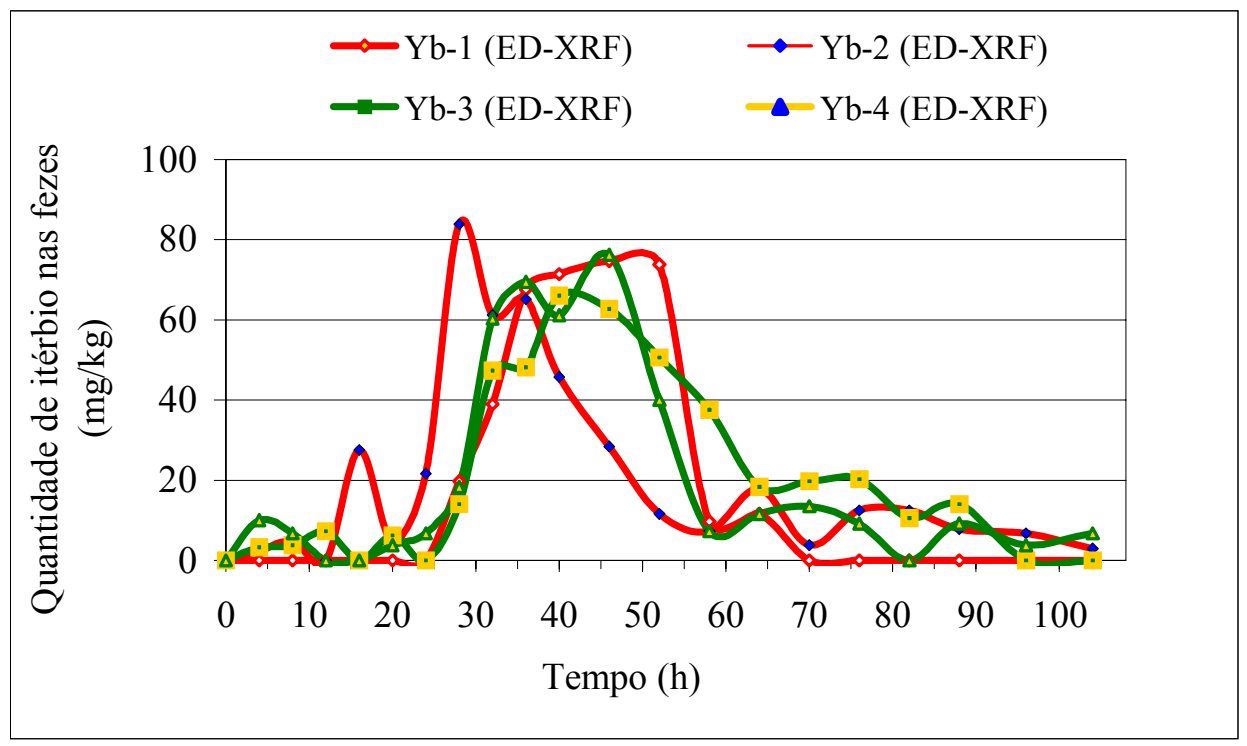

Figura 8 - Curva de excreção do itérbio, analisado por ED-XRF, para os quatro animais na Taxa de Passagem I. 
Para comparar essas curvas, as concentrações dos marcadores nas amostras de fezes foram transformadas em seus logaritmos naturais (ln), sendo realizada uma análise de regressão para cada tratamento utilizando o intervalo desde a concentração máxima de marcador encontrada nas fezes até a estabilização da curva (concentração $=0$ ). As equações lineares de regressão obtidas em cada tratamento encontram-se na Tabela 18.

Tabela 18. Equações de regressão linear e comparação dos valores de "b" para cada tratamento na Taxa de Passagem I

\begin{tabular}{lccc}
\hline \multicolumn{1}{c}{ Tratamentos } & Equação de regressão linear & $\mathrm{R}^{2}$ & $\begin{array}{c}\text { Comparação das } \\
\text { médias de "b" } 1,2\end{array}$ \\
\hline 1- Cr + ICP-OES & YLn $=11,49-0,074 . t$ & 0,72 & $-0,103^{\mathrm{a}}$ \\
2- Cr + ED-XRF & YLn $=11,93-0,086 . t$ & 0,82 & $-0,090^{\mathrm{a}}$ \\
3- La + ICP-OES & $\mathrm{YLn}=5,43-0,009 . \mathrm{t}$ & 0,35 & - \\
4- La + ED-XRF & $\mathrm{YLn}=5,52-0,039 . \mathrm{t}$ & 0,80 & $-0,042^{\mathrm{b}}$ \\
5- Yb + ICP-OES & $\mathrm{YLn}=4,89-0,023 . \mathrm{t}$ & 0,78 & $-0,024^{\mathrm{b}}$ \\
6- Yb + ED-XRF & $\mathrm{YLn}=5,50-0,035 . \mathrm{t}$ & 0,65 & $-0,037^{\mathrm{b}}$ \\
\hline
\end{tabular}

${ }^{\mathrm{T}}$ Médias seguidas por letras diferentes na mesma coluna diferem entre si pelo teste de Tukey $(\mathrm{P}<0,01)$

${ }^{2}$ Foram utilizadas as medias dos quatro animais na comparação dos valores de "b"

A taxa de passagem do La + ICP-OES não pôde ser levada em consideração tendo em vista que os dados não puderam ser ajustados satisfatoriamente em uma curva de regressão linear, gerando um coeficiente de determinação de 0,35. Esse resultado já era previsto pois o gráfico gerado por esses dados (Figura 5) apresentou um comportamento anormal, diferente dos demais tratamentos. Esse comportamento pode ser explicado por problemas na detecção do La, sugerindo que, em experimentos de taxa de passagem, quantidades maiores que $30 \mathrm{mg} / \mathrm{kg}$ de $\mathrm{La}$ devem ser utilizadas quando as amostras forem analisadas por ICP-OES.

Valores de "b" semelhantes foram encontradas para o cromo em animais submetidos à anastomose ileo-retal $(b=-0,090)$ e para animais canulados $(b=-0,070)$ (Leterne et al., 1991). Leterne et al. (1991), utilizando o Yb como marcador da fração fibrosa da dieta, encontraram maiores valores de "b" para os mesmos animais $(-0,13 \mathrm{e}-$ 
0,15 , respectivamente), indicando que a taxa de passagem da fração fibrosa foi maior que a da fração sólida (cromo).

Comparando os valores da inclinação da curva ("b"), pode-se observar que houve diferença entre marcadores na determinação da taxa de passagem. $\mathrm{O}$ cromo apresentou maior taxa de passagem em relação ao lantânio e o itérbio, independente da técnica analítica utilizada, sendo que estes não diferiram estatisticamente entre si $(\mathrm{P}>0,01)$ pelo teste de Tukey.

Essas diferenças encontradas podem ser decorrentes do método de incorporação das terras raras na dieta. Como o La e o $\mathrm{Yb}$ foram incorporados ao milho, a taxa de passagem encontrada para esses dois marcadores pode estar associada à taxa de passagem do milho, diferente do cromo que foi misturado em toda ração. A menor taxa de passagem do milho pode ser justificada por sua granulometria, partículas maiores possuem menor taxa de passagem que partículas finas (Imbeah et al. 1995).

A composição da dieta também pode interferir na determinação da taxa de passagem. Foram encontrados valores de -0,063 (Keys \& DeBarthe, 1974) e -0,056 (Imbeah et al., 1995) de taxa de passagem de rações contendo cevada e trigo em sua formulação. No Brasil, onde a ração basal de suínos é composta basicamente de milho e farelo de soja, não foram encontrados dados de taxa de passagem para comparação.

\subsubsection{Taxa de passagem II}

As Figuras 9 e 10, 11 e 12, 13 e 14 trazem as curvas de excreção do cromo, lantânio e itérbio, respectivamente, determinados pelas duas técnicas analíticas (ICP-OES e ED-XRF), expressos em concentração de marcador nas fezes ( $\mathrm{mg} / \mathrm{kg}$ ) com o tempo (h), após a interrupção do fornecimento dos marcadores na dieta $(2000 \mathrm{mg} / \mathrm{kg}$ de cromo e $60 \mathrm{mg} / \mathrm{kg}$ de lantânio e itérbio). 


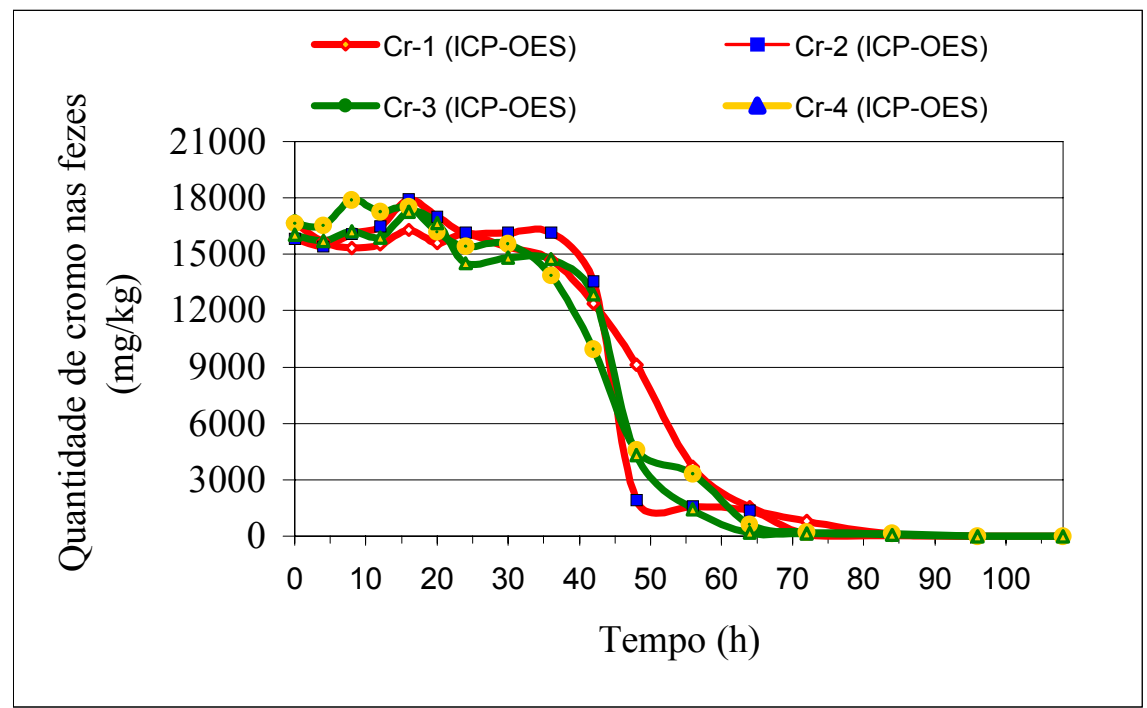

Figura 9 - Curva de excreção cromo, analisado por ICP-OES, para os quatro animais na Taxa de Passagem II.

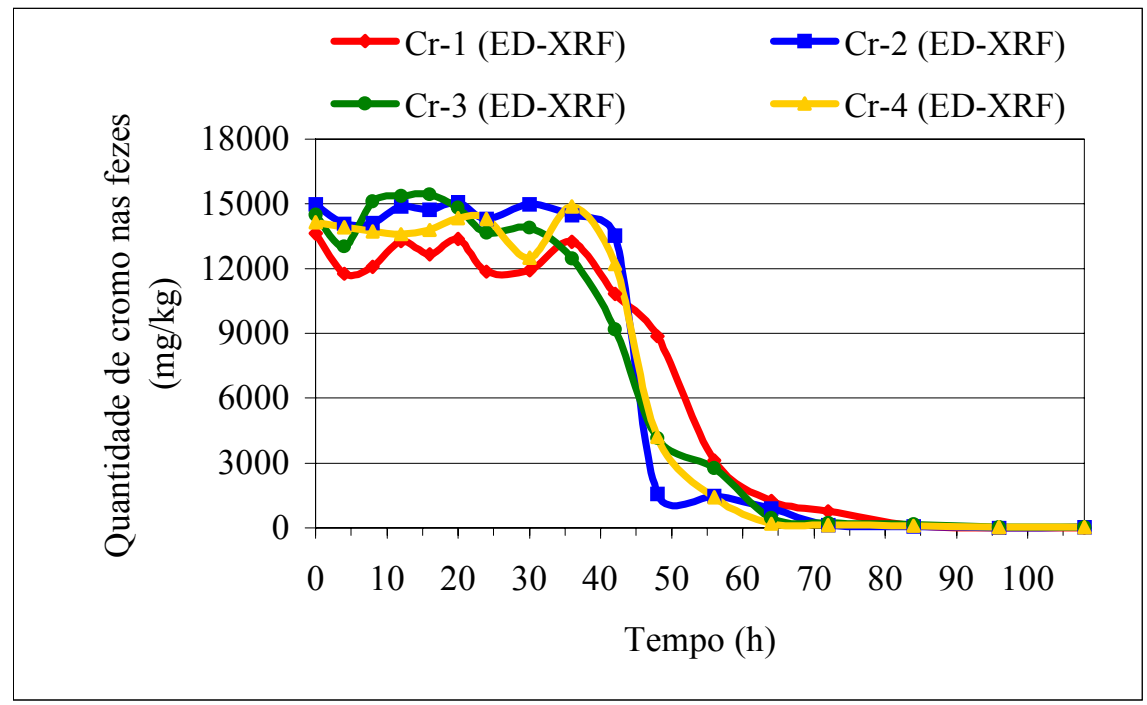

Figura 10 - Curva de excreção cromo, analisado por ED-XRF, para os quatro animais na Taxa de Passagem II. 


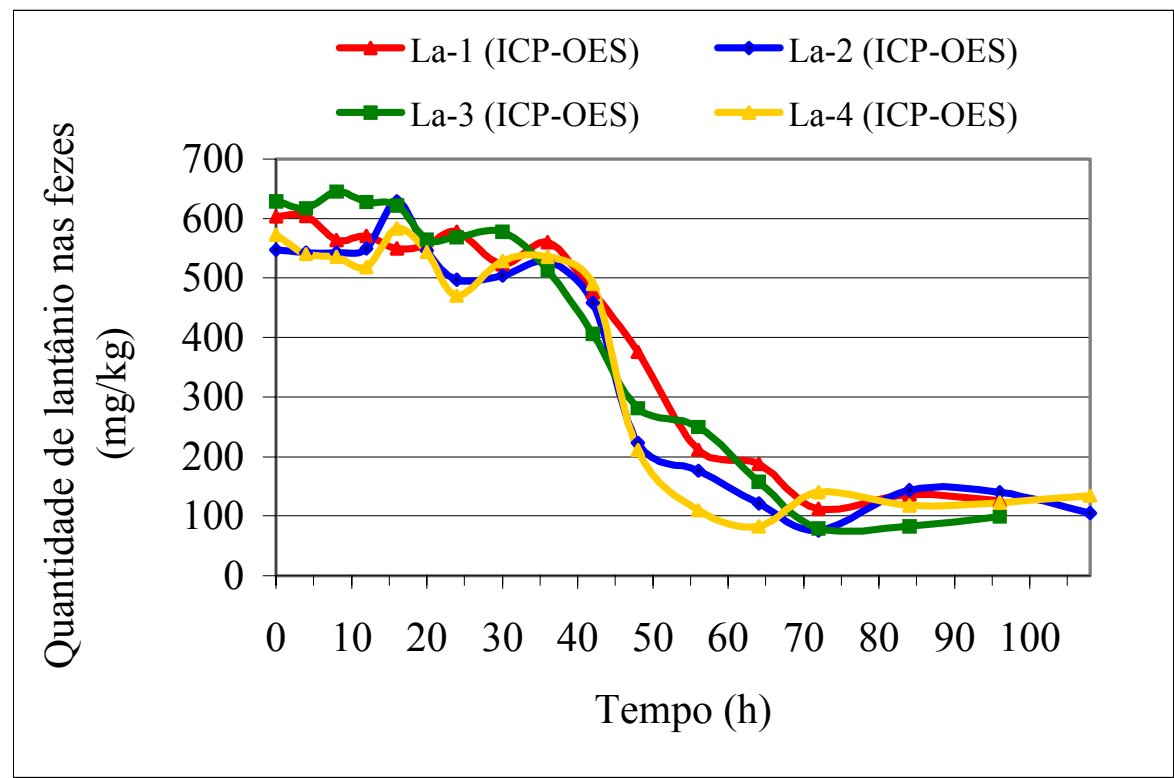

Figura 11 - Curva de excreção lantânio, analisado por ICP-OES, para os quatro animais na Taxa de Passagem II.

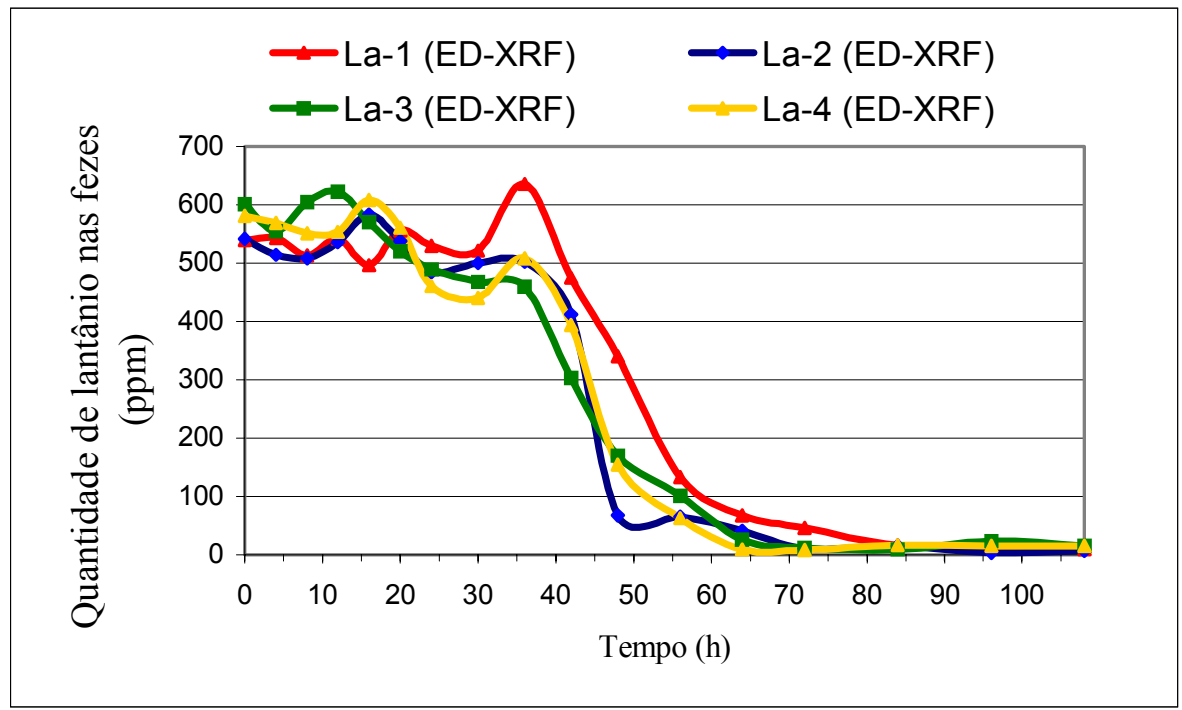

Figura 12 - Curva de excreção lantânio, analisado por ED-XRF, para os quatro animais na Taxa de Passagem II. 


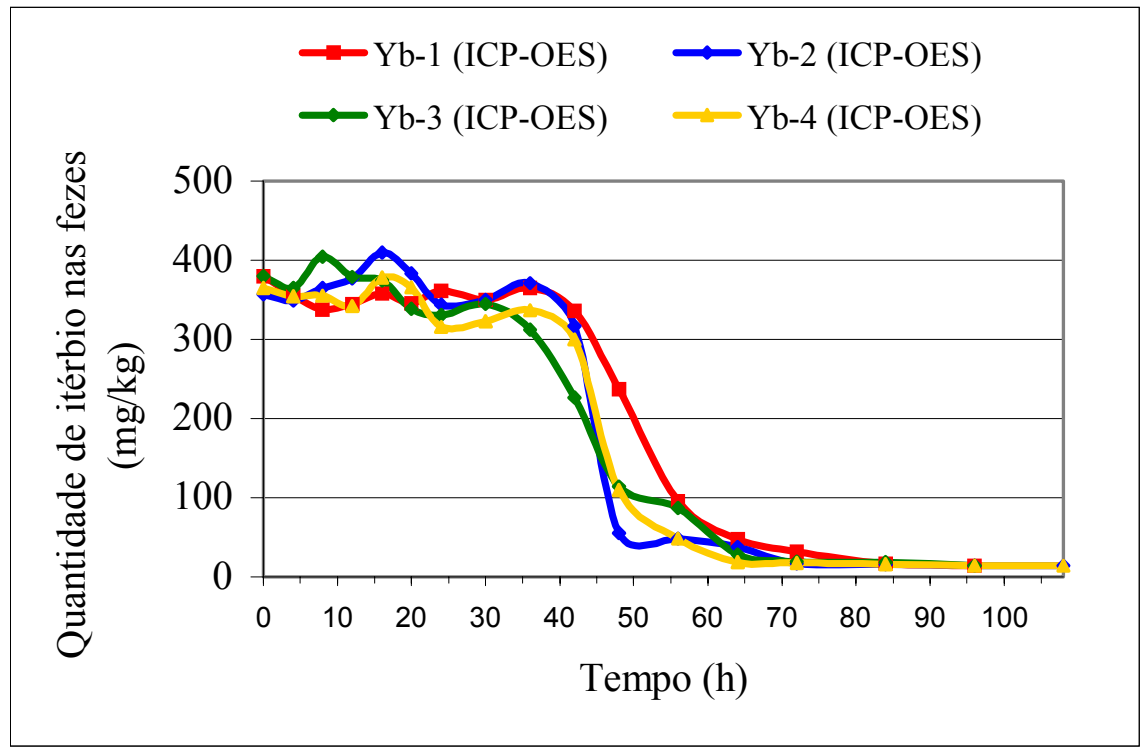

Figura 13 - Curva de excreção itérbio, analisado por ICP-OES, para os quatro animais na Taxa de Passagem II.

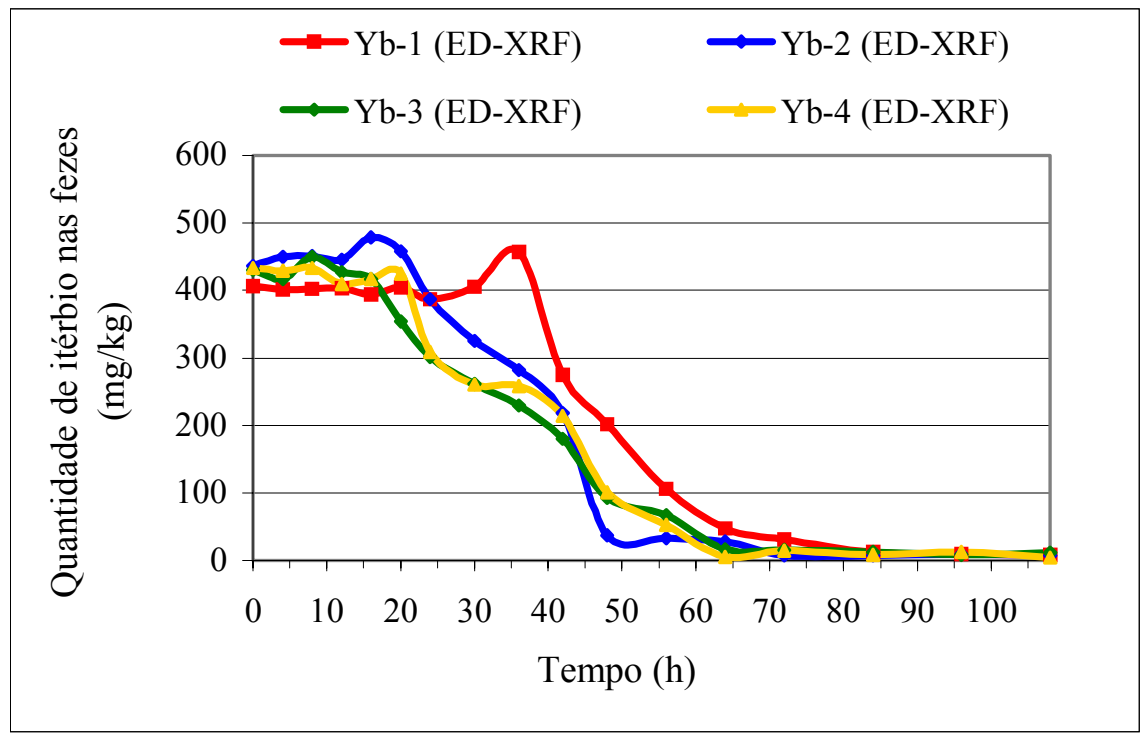

Figura 14 - Curva de excreção itérbio, analisado por ED-XRF, para os quatro animais na Taxa de Passagem II. 
Para comparar essas curvas, as concentrações dos marcadores nas amostras de fezes foram transformadas em seus logaritmos naturais (ln), sendo realizada uma análise de regressão para cada tratamento utilizando o intervalo desde a concentração máxima de marcador encontrada nas fezes até a estabilização da curva (concentração $=0$ ). As curvas da taxa de passagem foram comparadas pelo valor de "b" da equação linear de regressão encontrada para cada marcador. As equações de regressão linear obtidas em cada tratamento encontram-se na Tabela 19.

Tabela 19. Equações de regressão linear e comparação dos valores de "b" para cada tratamento na Taxa de Passagem II

\begin{tabular}{lccc}
\hline \multicolumn{1}{c}{ Tratamentos } & \multicolumn{1}{c}{ Equação } & $\mathrm{R}^{2}$ & $\begin{array}{c}\text { Comparação do } \\
\text { valor de "b" }\end{array}$ \\
\hline 1- Cr + ICP-OES & YLn $=11,11-0,065 . \mathrm{t}$ & 0,77 & $-0,072^{\mathrm{ab}}$ \\
2- Cr + ED-XRF & YLn $=11,43-0,079 . \mathrm{t}$ & 0,89 & $-0,082^{\mathrm{a}}$ \\
3- La + ICP-OES & YLn $=6,74-0,021 . \mathrm{t}$ & 0,80 & $-0,021^{\mathrm{d}}$ \\
4- La + ED-XRF & YLn $=7,57-0,055 . \mathrm{t}$ & 0,85 & $-0,056^{\mathrm{bc}}$ \\
5- Yb + ICP-OES & YLn $=6,70-0,040 . \mathrm{t}$ & 0,85 & $-0,040^{\mathrm{dc}}$ \\
6- Yb + ED-XRF & YLn $=6,94-0,051 . \mathrm{t}$ & 0,87 & $-0,055^{\mathrm{bc}}$ \\
${ }^{1}$ Médias seguidas por letras diferentes na mesma coluna diferem entre si pelo teste de Tukey (P<0,01) \\
${ }^{2}$ Foram utilizadas as medias dos quatro animais na comparação dos valores de "b"
\end{tabular}

Analisando os resultados da Tabela 19, nota-se que o cromo apresentou novamente maior taxa de passagem em relação aos demais tratamentos, entretanto, o Lantânio + ED-XRF não foi diferente estatisticamente do Cromo + ICP-OES pelo teste de Tukey a $1 \%$ de probabilidade. Os resultados do lantânio e itérbio também foram semelhantes, com exceção do Lantânio + ICP-OES que diferiu estatisticamente $(\mathrm{P}<0,01)$ dos tratamentos 4 (Lantânio + ED-XRF) e 6 (Itérbio + ED-XRF).

Esses resultados não apresentaram o mesmo comportamento que na Taxa de Passagem I provavelmente porque, desta vez, metade da quantidade de lantânio e itérbio marcou o milho, e a outra metade marcou a ração. Com isso, os valores de "b" ficaram mais próximos do valor encontrado para o cromo, sem entretanto, serem 
considerados iguais estatisticamente (exceção para o Lantânio + ED-XRF e Itérbio + ED-XRF em relação ao Cromo + ICP-OES).

Em relação à técnica analítica, observa-se que o único marcador que apresentou valores de " $b$ " estatisticamente diferentes entre as duas técnicas de análise foi o lantânio (-0,021 para ICP-OES e - 0,055 para ED-XRF).

\subsubsection{Comparação entre as taxas de passagem I e II}

As comparações entre as taxas de passagem foram feitas pelos valores de "b" encontrados para cada tratamento, nas duas taxas de passagem, através da análise de variância (Tabela 20).

Tabela 20. Comparação dos valores médios do "b" da equação de regressão linear obtidos nas Taxas de Passagem I e II para cada um dos tratamentos

\begin{tabular}{|c|c|c|c|c|}
\hline Tratamento & $\begin{array}{c}\text { Taxa de } \\
\text { passagem }\end{array}$ & $\begin{array}{c}\text { Valores } \\
\text { médios de "b" }\end{array}$ & $\begin{array}{l}\text { Diferença entre } \\
\text { os valores de "b" }\end{array}$ & $\begin{array}{c}\text { Valores médios } \\
\text { do } \mathrm{R}^{2} \\
\end{array}$ \\
\hline \multirow{2}{*}{ Cromo + ICP-OES } & $\mathrm{I}$ & $-0,103$ & \multirow{2}{*}{$0,031^{*}$} & 0,93 \\
\hline & II & $-0,072$ & & 0,84 \\
\hline \multirow{2}{*}{ Cromo + ED-XRF } & $\mathrm{I}$ & $-0,090$ & \multirow{2}{*}{0,008} & 0,96 \\
\hline & II & $-0,082$ & & 0,90 \\
\hline \multirow{2}{*}{ Lantânio + ICP-OES } & $\mathrm{I}$ & - & \multirow{2}{*}{ - } & 0,43 \\
\hline & II & $-0,021$ & & 0,80 \\
\hline \multirow{2}{*}{ Lantânio + ED-XRF } & I & $-0,042$ & \multirow{2}{*}{0,014} & 0,88 \\
\hline & II & $-0,056$ & & 0,88 \\
\hline \multirow{2}{*}{ Itérbio + ICP-OES } & $\mathrm{I}$ & $-0,024$ & \multirow{2}{*}{0,016} & 0,85 \\
\hline & II & $-0,040$ & & 0,87 \\
\hline \multirow{2}{*}{ Itérbio + ED-XRF } & I & $-0,037$ & \multirow{2}{*}{0,018} & 0,70 \\
\hline & II & $-0,055$ & & 0,91 \\
\hline
\end{tabular}

\footnotetext{
* As médias diferem significativamente entre si pelo Teste de $\mathrm{F}(\mathrm{P}<0,01)$
} 
$\mathrm{O}$ único tratamento que apresentou diferença significativa $(\mathrm{P}<0,01)$ entre as duas determinações de taxa de passagem foi o Cromo + ICP-OES. Para os demais tratamentos não foram encontradas diferenças significativas entre as taxas de passagem I e II, ratificando resultados encontrados por Imbeah et al. (1995).

Apesar de não terem sido observadas diferenças significativas entre as taxas de passagem, sugere-se optar por aquelas que apresentem maior ajuste da equação e, portanto, maior coeficiente de determinação. Sendo assim, para o cromo, independente da técnica analítica utilizada, os resultados mais consistentes foram obtidos na Taxa de Passagem I, diferentemente do Itérbio + ED-XRF, onde o melhor resultado foi obtido na Taxa de Passagem II.

A escolha de um marcador ideal para medir taxa de passagem é muito complexa, pois não existe um tratamento padrão como forma de comparação. Outros estudos precisam ser feitos para determinar os marcadores mais apropriados ao tipo de dieta, em estudos de taxa de passagem com suínos. 


\section{CONCLUSÃO}

Existe diferença entre o método da coleta total de fezes e a coleta parcial de fezes para determinação da digestibilidade aparente dos nutrientes dietéticos em suínos. Essa diferença pode ser proveniente dos marcadores utilizados, da concentração dos marcadores na ração utilizada nos cálculos, da técnica analítica utilizada na determinação dos marcadores e da baixa porcentagem de recuperação dos marcadores nas fezes.

No ensaio de digestibilidade, melhores resultados foram obtidos utilizando o cromo + ICP-OES e lantânio + ED-XRF, sendo que a diferença em relação ao tratamento padrão foi de aproximadamente $3 \%$.

Apesar do lantânio ter apresentado resultados promissores em comparação aos demais marcadores, outros estudos precisam ser feitos para avaliar e comprovar a eficácia do uso de terras raras em ensaios de digestibilidade com suínos.

Em relação à taxa de passagem, pode-se concluir também que não existe diferença significativa entre os dois métodos de determinação, com exceção do cromo + ICP-OES. O cromo apresentou uma maior taxa de passagem que o lantânio e o itérbio. Esta menor taxa de passagem observada para o lantânio e o itérbio pode ser um indicativo da menor taxa de passagem do milho em relação à ração. 


\section{REFERÊNCIAS BIBLIOGRÁFICAS}

ABDALLA, A.L.; SUTTON, J.D.; PHIPPS, R.H.; HUMPHRIES, D.J. Digestion in the rumen of lactating dairy cows given mixtures of urea-treated whole-crop wheat and grass silage. Animal Science, v.69, n.1, p.203-212, 1999.

ANDRIGUETTO, J.M.; PERLY, L.; MINARDI, I. Nutrição animal. 2.ed. São Paulo: Nobel, 1988. v.1, p.71-75.

ASSOCIATION OF OFFICIAL AGRICULTURAL CHEMISTIS (A.O.A.C.). Official methods of analysis. 12.ed. Washington, 1995.

BAKER, G.C.M.; JONGBLOED, A.W. The effect of housing system on apparent digestibility in pigs, using the classical and marker (chromic oxide, acid-insoluble ash) techniques, in relation to dietary composition. Journal of the Science of Food and Agriculture, v.64, p.107-115, 1994.

BERNARD, L.; DOREAU, M. Use of rare earth elements as external markers for mean retention time measurements in ruminants. Reproduction Nutrition Development, v.40, p.89-101, 2000. 
BRANDYBERRY, S.D.; COCHRAN, R.C.; VANZANT, E.S.; HARMON, D.L. Technical note: effectiveness of different methods of continuous marker administration for estimating fecal output. Journal of Animal Science, v.69, p.4611-4616, 1991.

CASTLE, E.J.; CASTLE, M.E. Further studies of the rate of passage of food through the alimentary tract of pigs. Journal of Agricultural Science, v.49, p.106-112, 1957.

EHLE, F.R.; JERACI, J.L.; ROBERTSON, J.B.; VAN SOEST, P.J. The influence of dietary fiber on digestibility, rate of passage and gastrointestinal fermentation in pigs. Journal of Animal Science, v.55, p.1071-1081, 1982.

FURUYA, S.; SAKAMOTO, K.; ASANO, T.; TAKAHASHI, S.; KAMEOKA, K. Effects of added dietary sodium polycrylate of passage rate of markers and apparent digestibility by growing swine. Journal of Animal Science, v.47, n.1, p.159-165, 1978.

HOLZGRAEFE, P.D.; FAHEY, G.C.; JENSEN, A.H. Influence of dietary alfafa:orchardgrass hay and lasalocid on in vitro estimates of dry matter digestibility and volatile fatty acid concentrations of cecal contents and rate of digesta passage in sows. Journal of Animal Science, v.60, n.5, p.1235-1246, 1985. 
IMBEAH, M.; SAUER, W.C. The effect of dietary fat level on amino acid digestibilities and the rate of passage of soybean meal and canola meal diets for growing pigs. Livestock Production Science, v.29, p.227-239, 1991.

IMBEAH, M.; SAUER, W.C.; CAINE, W.R. Comparison of the single dose and withdrawal method for measuring the rate of passage of two digestibility markers in digesta collected from the distal ileum and feces in growing pigs. Animal Feed Science and Technology, v.52, p.41-50, 1995.

JAGGER, S.; WISEMAN, J.; COLE, D.J.A.; CRAIGON, J. Evaluation of inert markers for the determination ileal and faecal apparent digestibility values in the pig. British Journal of Nutrition, v.68, p.729-739, 1992.

KASS, M.L.; Van SOEST, P.J.; POND, W.G.; LEWIS, B.; McDOWELL, R.E. Utilization of dietary fiber from alfafa by growing swine. I. Apparent digestibility of diet components in specific segments of the gastrointestinal tract. Journal of Animal Science, v.50, p.175-191, 1980.

KAVANAGH, S.; LYNCH, P.B.; MARA, F.O.; CAFFREY, P.J. A comparison of total collection and marker technique for measurement of apparent digestibility of diets for growing pigs. Animal Feed Science and Technology, v.89, p.49-58, 2001.

KAY, M.A.; HUTCHESON, D.W.; VALES, J.; HARTMAN, R.; GOECKLER, W.; LUCKEY, T.D. Fate of rare earth oxide dietary markers in rats and pigs. Nutrition Reports International, v.21, p.323-327, 1980. 
KEYS, J.E.; DeBARTHE, J.V. Site and extent of carbohydrate, dry matter, energy and protein digestion and rate of passage of grazing swine. Journal of Animal Science, v.39, p.57-62, 1974.

KOHLER, T.; HUISMAN, J., HARTOG, L.A.; MOSENTHIN, R. Comparison of different digesta collection methods to determine apparent digestibilities of the nutrients at the terminal ileum in pigs. Journal of the Science of Food and Agriculture, v.53, p.465-475, 1990.

KOTB, A.R.; LUCKEY, T.D. Markers in nutrition. Nutrition Abstracts and Reviews, v.42, n.3, p.814-845, 1972.

KOZLOSKI, G.V.; FLORES, E.M.M.; MARTINS, A.F. Use of chromium oxide in digestibility studies: variations of the results as a function of the measurement method. Journal of the Science of Food and Agriculture, v.76, p.373-376, 1998.

LIMA, E.C.; KRUG, F.J.; NÓBREGA, J.A.; NOGUEIRA, A.R.A. Determination of ytterbium in animal faeces by tungsten coil atomic absorption spectrometry. Talanta, v.47, p.613-623, 1998.

LETERME, P.; PIRARD, L.; THEWIS, A.; FRANÇOIS, E. A note on the rate of passage of digesta in pigs ileo-rectostomized or fitted with an ilea T-cannula. Animal Production, v.53, p.253-256, 1991. 
McCARTHY, J.F.; AHERNE, F.X..; OKAI, D.B. Use of acid insoluble ash as an index material for determining apparent digestibility with pigs. Canadian Journal of Animal Science, v.54, p.107-109, 1974.

McCARTHY, J.F.; BOWLAND, J.P., AHERNE, F.X. Influence of method upon the determination of apparent digestibility in the pig. Canadian Journal of Animal Science, v.57, p.131-135, 1977.

MANBRINI, M.; PEYRAUD, J.L. Retention time of feed particles and liquids in the stomachs and intestines of dairy cows. Direct measurement and calculations based on faecal collection. Reproduction Nutrition Development, v.37, p.427-442, 1997.

MOORE, J.A.; SWINGLE, R.S. Standard operating procedures. In: POORE, M.H. Rumen passage rates and fiber digestibilities for wheat, straw, alfafa hay, and flaked sorghum grain in mixed diets for steers. Tucson, 1987. Thesis (M.S.) - University of Arizona.

MOORE, J.A.; POND, K.R.; POORE, M.H.; GOODWIN, T.G. Influence of model and marker on digesta kinetic estimates for sheep. Journal of Animal Science, v.70, p.3528-3540, 1992

MOREIRA, I.; ROSTAGNO, H.S.; COELHO, D.T.; COSTA, P.M.A.; TAFURI, M.L. Determinação dos coeficientes de digestibilidade, valores energéticos e índices de controle de qualidade do milho e soja integral processados a calor. Revista Brasileira de Zootecnia, v.23, p.917-929, 1994. 
MOREIRA, I.; OLIVEIRA, G.C.; FURLAN, A.C.; PATRICIO, V.M.I.; JUNIOR, M.M. Utilização da farinha pré-gelatinizada de milho na alimentação de leitões na fase de creche. Digestibilidade e desempenho. Revista Brasileira de Zootecnia, v.30, p.440-448, 2001.

MOUGHAN, P.J.; SMITH, W.C.; SCHRAMA, J.; SMITS, C. Chromic oxide and acidinsoluble ash as faecal markers in digestibility studies with young pigs. New Zealand Journal of Agricultural Research, v.34, p.85-88, 1991.

MROZ, Z.; BAKKER, G.M.C.; JONGBLOED, A.W.; DEKKER, R.A.; JONGBLOED, R.; BEERS, A.V. Apparent digestibility of nutrients in diets with different energy density, as estimated by direct and marker methods for pigs with or without íleocecacl cannulas. Journal of Animal Science, v.74, p.403-412, 1996.

NASCIMENTO FILHO, V.F. Técnicas analíticas nucleares de fluorescência de raios $X$ por dispersão de energia (ED-XRF) e por reflexão total (TXRF). http://panda/apostilas/virgilio/cen-5723/EDXRF_TXRF.doc (20/03/2002)

NEVES, A.C.E. Estudo da composição química, da digestibilidade, da aditividade e dos valores energéticos de alguns alimentos para suínos em duas fases. Viçosa, 1993. 63p. Dissertação (M.S.) - Universidade Federal de Viçosa. 
NOGUEIRA, A.R.A.; LOPES, G.S.; LIMA, E.C.; WANDERLEY, R.C.; SILVA, A.G.; KRUG, F.J. Determinação do fluxo de múltiplos marcadores de digesta em carneiros utilizando técnicas alternativas de análise. In: REUNIÃO ANUAL DA SOCIEDADE BRASILEIRA DE ZOOTECNIA, 34., Juiz de Fora, 1997. Resumos. Juiz de Fora: SBZ, 1997. p.134-136.

OLIVEIRA, V. Casca de café em rações isoenergéticas para suínos em crescimento e terminação (digestibilidade e desempenho). Lavras, 1999. 61p. Dissertação (Mestrado) - Universidade Federal de Lavras.

POND, K.R.; ELLIS, W.C.; JAMES, W.D.; DESWYSEN, A.G. Analysis of multiple markers in nutrition research. Journal of Dairy Science, v.68, p.745-750, 1985.

POND, W.G.; POND, K.R.; ELLIS, W.C.; MATIS, J.H. Markers for estimating digesta flow in pigs and the effects of dietary fiber. Journal of Animal Science, v.63, p.1140-1149, 1986.

POORE, M.H.; MOORE, J.A.; ECK, T.P.; SWINGLE, R.S. Influence of passage model, sampling site, and marker dosing time on passage of rare earth-labeled grain through Holstein cows. Journal of Animal Science, v.69, p.2646-2654, 1991.

RYSSEN, J.B.J.; MAVIMBELA, D.T. Broiler litter as a source of selenium for sheep. Animal Feed Science and Technology, v.78, p.263-272, 1999. 
SAHA, D.C.; GILBREATH, R.L. Analytical recovery of chromium from diet and faeces determined by colorimetry and atomic absorption spectrophotometry. Journal of the Science of Food and Agriculture, v.55, p.433-436, 1991.

SAS INSTITUTE. SAS user's guide: statistics. Cary: Statistical Analysis System Institute, 2000.

SATTER, L.D.; COMBS, D.K.; LOPEZ-GUISA, J.M.; NELSON, W.F. Use of markers for measurement of feed digestibility in ruminants. In: INTERNATIONAL SYMPOSIUM ON THE USE OF NUCLEAR TECHNIQUES IN STUDIES OF ANIMAL PRODUCTION AND HEALTH IN DIFFERENT ENVIRONMENTS, Vienna, 1986. Proceedings. Vienna: IAEA, 1986. p.469-484.

SCHIAVON, S.; RAMANZIN, M.; BITTANTE, G.; GALLO, L. Comparison between total collection and chromic oxide techniques for the evaluation of pig apparent digestibility with different diets and different adaptation and collection periods. Zootecnia e Nutrizione Animale, v.22, p.23-32, 1996.

SCHNEIDER, B.H.; FLATT, W.P. The evaluation of feeds through digestibility experiments. Athens: The University of Georgia Press, 1975. 423p.

SEERLEY, R.W.; MILLER, E.R.; HOEFER, J.A. Rate of food passage studies with pigs equally and ad libitum fed meal and pellets. Journal of Animal Science, v.21, p.834-837, 1962. 
SIDDONS, R.C.; PARADINE, J.; BEEVER, D.E.; CORNELL, P.R. Ytterbium acetate as a particulate-phase digesta-flow marker. British Journal of Nutrition, v.54, p.509-519, 1985.

SOUZA, A.V.C.; FONTES, D.O.; LOPES, D.C.; DONZELE, J.L.; LOPES, M.A.F.; ANTUNES, F. Comparação entre indicadores externos, internos e o método de coleta total de fezes em ensaios de digestibilidade com suínos. In: REUNIÃO ANUAL DA SOCIEDADE BRASILEIRA DE ZOOTECNIA, 35., Botucatu, 1998. Resumos. Botucatu: SBZ, 1998. p.365-366.

TITGEMEYER, E.C. Design and interpretation of nutrient digestion studies. Journal of Animal Science, v.75, p.2235-2247, 1997.

UDÈN, P.; COLUCCI, P.E.; VAN SOEST, P.J. Investigation of chromium, cerium and cobalt as markers in digesta. Rate of passage studies. Journal of the Science of Food and Agriculture, v.31, p.625-632, 1980.

ULUSOY, U.; WHITLEY, J.E. Determination of intestinal uptake of iron and zinc using stable isotopic tracers and rare earth markers. Nutrition Research, v.19, p.675-688, 1999.

VAREL, V.H.; JUNG, H.G.; POND, W.G. Effects of dietary fiber of young adult genetically lean, obese and contemporary pigs: rate of passage, digestibility and microbiological data. Journal of Animal Science, v.66, p.707-712, 1988. 
WHITBY, L.G.; LANG, D. Experience with the chromic oxide method of fecal marking in metabolic balance investigations of humans. Journal of Clinical Investigation, v.39, p.854-859, 1960.

YIN, Y.L.; McEVOY, J.D.G; SCHULZE, H.; HENNING, U.; SOUFFRANT, W.B.; McCRACKEN, K.J. Apparent digestibility (ileal and overall) of nutrients as evaluated with PVTC-cannulated or ileo-rectal anastomised pigs fed diet containing two indigestible markers. Livestock Production Science, v.62, p.133-141, 2000a.

YIN, Y.L.; McEVOY, J.D.G.; SCHULZE, H.; McCRACKEN, K.J. Studies on cannulation method and alternative indigestible markers and the effects of food enzyme supplementation in barley-based diets on ileal and overall apparent digestibility in growing pigs. Animal Science, v.70, p.63-72, $2000 \mathrm{~b}$.

YOUNG, L.G.; LOW, A.G.; CLOSE, W.H. Digestion and metabolism techniques in pigs. In: MILLER, E.R.; ULLREY, D.E.; LEWIS, A.J. Swine nutrition. Stoneham: Butterworth-Heineman, 1991. cap.39, p.623-630. 


\section{ERRATA}

Tabela 16. Porcentagem de recuperação ${ }^{a}$ dos marcadores $(\mathrm{Cr}$, La e $\mathrm{Yb})$, analisados por ICPOES e ED-XRF, nas fezes de suínos em terminação

\begin{tabular}{|c|c|c|c|c|c|c|}
\hline & \multicolumn{3}{|c|}{ ICP-OES } & \multicolumn{3}{|c|}{ ED-XRF } \\
\hline & Cromo & Lantânio & Itérbio & Cromo & Lantânio & Itérbio \\
\hline Ração $^{b}$ & 0,19 & 91,03 & 66,22 & 0,22 & 60,86 & 56,56 \\
\hline \multicolumn{7}{|l|}{ Animal } \\
\hline 1 & 67,588 & 56,425 & 46,932 & 51,516 & 69,889 & 52,909 \\
\hline 2 & 94,287 & 81,167 & 68,477 & 69,695 & 100,433 & 89,222 \\
\hline 3 & 91,524 & 72,120 & 65,204 & 67,336 & 101,061 & 79,363 \\
\hline 4 & 78,868 & 68,111 & 56,269 & 55,273 & 78,675 & 65,574 \\
\hline 5 & 72,577 & 61,071 & 51,547 & 52,352 & 77,946 & 52,469 \\
\hline 6 & 97,204 & 75,759 & 69,754 & 68,813 & 93,360 & 85,958 \\
\hline 7 & 89,017 & 70,652 & 61,598 & 65,932 & 91,750 & 82,842 \\
\hline 8 & 70,925 & 63,196 & 50,015 & 51,304 & 70,328 & 56,460 \\
\hline 9 & 67,394 & 54,336 & 48,646 & 47,058 & 66,793 & 56,242 \\
\hline 10 & 78,573 & 63,108 & 53,364 & 52,660 & 74,604 & 66,529 \\
\hline 11 & 81,450 & 63,997 & 57,585 & 60,080 & 82,491 & 71,896 \\
\hline 12 & 82,326 & 66,682 & 59,834 & 56,674 & 80,565 & 68,030 \\
\hline Média & 80,97 & 66,38 & 57,43 & 58,22 & 82,32 & 68,958 \\
\hline $\mathrm{CV}^{\mathrm{c}}(\%)$ & 12,70 & 11,70 & 13,40 & 13,50 & 14,30 & 18,20 \\
\hline
\end{tabular}

Tabela 17. Comparação entre a porcentagem de recuperação dos marcadores nas fezes (analisados por ICP-OES e ED-XRF) considerando a concentração esperada e a concentração analisada de marcadores na ração

\begin{tabular}{|c|c|c|c|c|c|}
\hline $\begin{array}{c}\text { Técnica } \\
\text { analítica }\end{array}$ & Marcador $^{\mathrm{b}}$ & $\begin{array}{l}\text { Quantidade } \\
\text { esperada }^{\mathrm{b}}\end{array}$ & $\begin{array}{l}\text { Quantidade } \\
\text { encontrada }^{b}\end{array}$ & $\begin{array}{c}\text { \% Recuperação }{ }^{a} \\
\text { (esperada) }\end{array}$ & $\begin{array}{c}\text { \% Recuperação } \\
\text { (analisada) }\end{array}$ \\
\hline \multirow{3}{*}{ ICP-OES } & Cromo & 0,20 & 0,19 & 76,79 & 80,97 \\
\hline & Lantânio & 60,00 & 91,03 & 99,70 & 66,38 \\
\hline & Itérbio & 60,00 & 66,20 & 61,63 & 57,43 \\
\hline \multirow{3}{*}{ ED-XRF } & Cromo & 0,20 & 0,22 & 62,75 & 58,22 \\
\hline & Lantânio & 60,00 & 60,86 & 83,61 & 82,32 \\
\hline & Itérbio & 60,00 & 56,56 & 65,08 & 68,95 \\
\hline
\end{tabular}

